\title{
Boiling Heat Transfer: Mechanisms, Models, Correlations and the Lines of Further Research
}

\author{
Irakli G. Shekriladze* \\ Department of Thermophysics, Georgian Technical University, Georgia
}

\begin{abstract}
A review discusses current status of boiling heat transfer research. Basic experimental facts, physical models and correlations of experimental data on heat transfer coefficient (HTC) are reconsidered. Principal restrictions of traditional model of "the theatre of actors" (MTA) are demonstrated. Basic role of control of HTC by thermodynamic conditions on nucleation sites is demonstrated and consequent model of "the theatre of director" (MTD) is discussed. Universal MTD-based correlation of boiling HTC of all types of liquids is presented. Unified consistent research framework for developed boiling heat transfer and diverse specific boiling heat transfer regimes is outlined through supplementing MTD by so-called multifactoring concept (MFC). MFC links transition from developed boiling mode to diverse boiling curves to a phenomenon of multiplication of factors influencing HTC. Multifactoring phenomenon equally can cover any boiling process including boiling in minichannels and microchannels. Possible types of multifactoring are considered. Finally, the ways of further research of the boiling problem are discussed.
\end{abstract}

Keywords: Boiling, nucleation, heat transfer, heat transfer coefficient, heat transfer crisis.

\section{INTRODUCTION}

Complexity of boiling phenomenon is connected with combination of phase conversion and turbulence in an area with irregular internal structure. Importance of boiling heat transfer research is determined by wide sphere of application covering thermal and nuclear power engineering, space, aviation, cryogenic, refrigeration, chemical, food and other technologies.

A history of boiling heat transfer research represents an impressive example how unwillingness to deconstruct internal contradictions of applicable approaches leads to theoretical deadlock.

The first internal contradiction of traditional approach manifests itself between linking of HTC to intensity of concrete cooling mechanisms (a model of "the theatre of actors" (MTA) and real independence of heating surface superheat on changes of intensities of the same concrete cooling mechanisms.

Drastic changes in inter-phase hydrodynamics occurring with a change in the intensity of body force by several orders of magnitude, with forced convection or subcooling, with change of sizes and thermal parameters of heating surface, all of these changes have virtually no influence on heating surface superheat in the mode of developed boiling.

The main outcome of such a situation is widely known by way of numerous unsuccessful attempts of MTA-based correlation of experimental data on HTC during boiling of different groups of liquids.

The second widely used misassumption attributes universally leading role in boiling heat transfer to

*Address correspondence to this author at the Georgian Technical University - Department of Thermophysics, Kostava Street 77, 1075 Tbilisi, Georgia; E-mail: shekri@geo.net.ge microlayer evaporation mechanism based only on synchronism of heating wall temperature drop with the onset of a bubble growth (against numerous experiments reflecting major role of liquid phase convection in the majority of boiling processes).

Simultaneously, the same history of boiling heat transfer research represents no less impressive example how resolution of existing contradictions opens up the ways to breakthrough in the theory.

For instance, resolution of aforementioned first contradiction leads to a model of "the theatre of director" (MTD) and universal correlation of experimental data on boiling HTC of all types of liquids opening a new avenue of attack on the problem.

In the same way, resolution of aforementioned second contradiction reveals existence of the pumping effect of growing bubble (PEGB) playing crucial role in boiling heat transfer and hydrodynamics.

Unfortunately, aforementioned misleading common background proves to be so strong that MTD and PEGB still have unnoticeable influence on the main lines of boiling heat transfer research.

Simultaneously abovementioned situation exerts certain impact on modern reviews of the problem [1-3]. It becomes topical to reanalyze modern state of boiling research [4]. An attempt to bridge this gap is made below.

Basic features of boiling phenomenon, experimental facts and physical models are reconsidered. Alternative approaches to boiling heat transfer problem (MTA and MTD) and following from them correlations are examined. Unified consistent research framework for developed boiling heat transfer and diverse specific boiling heat transfer regimes is outlined by way of supplementing of MTD by so-called multifactoring concept (MFC). In the framework of MFC potential role of PEGB is considered in generation of strong reverse vapor follows, related cyclical oscillations and flow 
instabilities observed in minichannels and microchannels. The ways of further research of the boiling problem are discussed.

\section{BASIC FEATURES AND EXPERIMENTAL FACTS}

The basic part of boiling heat transfer curve corresponds to so-called developed boiling mode. By common agreement developed boiling means a process with decisive contribution of cooling mechanisms unique to boiling itself. Such a boiling mode is observed in rather wide range of heat fluxes between the zones with tangible effect of natural or forced convection and boiling crisis. This is why developed boiling mode may cover different ranges of heat fluxes at constant pressure depending on geometry of boiling surface, intensity of gravity field, subcooling or liquid flow.

However, developed boiling heat transfer law (for instance, dependence between heat flux and heating surface superheat) remains uniform.

Characteristic for boiling another feature is diversity of cooling mechanisms contributing in heat transfer.

In boiling of saturated single-component liquid one can distinguish three basic cooling mechanisms associated with boiling itself. Among them only one (microlayer evaporation [5]) is linked to immediate evaporation on boiling surface (Fig. 1a). Other two mechanisms (bubbling $[6,7]$ (Fig. 1b) and jet-like [8] (Fig. 1c) are linked to liquid phase convection.

Cooling mechanisms operating through pushing the liquid by growing bubble, through displacement of overheated liquid layer (transient conduction dominated model) or through drift liquid current subsequent to detached bubble (sometimes thought to be separate mechanisms) can presumably be regarded as being separate stages of action of bubbling mechanism.
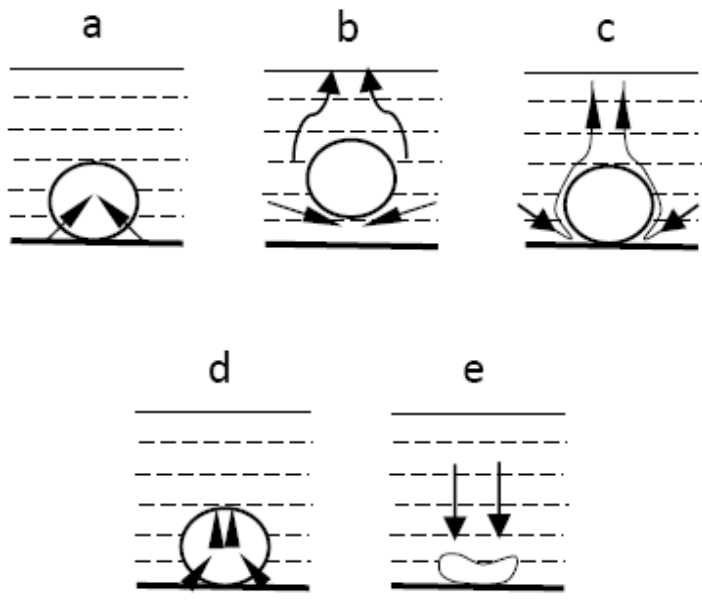

Fig. (1). Schemes of different cooling mechanisms.

Subcooling of liquid phase puts in operation two additional cooling mechanisms: evaporation-condensation [9] (Fig. 1d), being an extra version of the microlayer evaporation mechanism, and quasi-cavitations [10] (Fig. 1e) associated with the collapse of a bubble on the surface under the influence of subcooled liquid. It also belongs to a number of convection mechanisms micro-membrane pumping effect [11] (this poorly known dynamical effect of nongravity nature is discussed below).

\section{Microlayer Evaporation}

Discovery of heating surface temperature pulsation synchronous with a bubble formation and departure cycle [5] has led to qualitative deepening of understanding of boiling phenomenon.

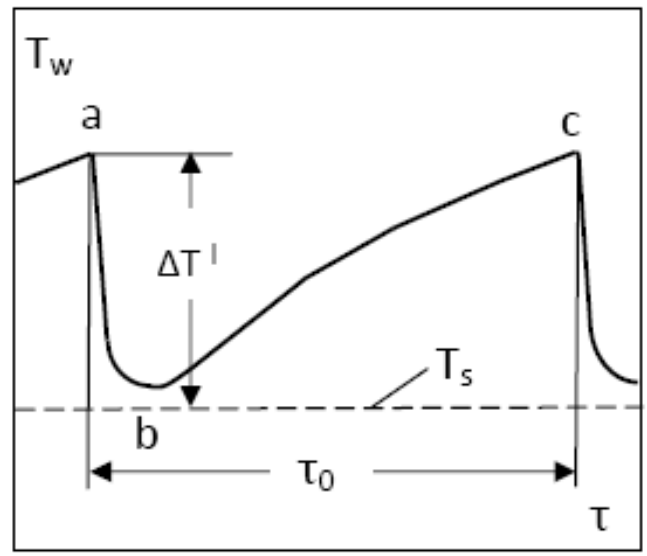

Fig. (2). Typical cycle of local temperature pulsation on heating surface [5].

Fundamental outcome of this and further studies of local temperature pulsations is establishment of coincidence of main cooling effect with onset of bubble growth (Fig. (2), points a and c). It also is important establishment of short-run character of intensive cooling effect (duration of intensive cooling is far less than duration of the cycle).

At the same time, in the same and in a number of further studies, exclusive role is attributed to microlayer evaporation in fixed cooling effect based only on the synchronism of temperature drop and the onset of a bubble growth. Besides, no evaluations are made of the capability of microlayer evaporation to absorb heat released by heating surface during temperature drop.

In contrast to it, questionably leading role of microlayer evaporation even in cooling of underlying local zone of heating surface is shown in an analysis [8]. Significant excess of heat removed from the boiling surface over the quantity that might be absorbed by the bubble of departure size also is revealed in experiments [12-14].

According these results fundamental evidences of dominant role of liquid phase convection in boiling heat transfer [6, 15-17] remain in force regarding to local temperature pulsations as well.

Contradiction between arising of main cooling effect at the onset of bubble growth and deficient capacity of microlayer to absorb released heat was resolved through prediction of existence of so-called pumping effect of growing bubble (PEGB) [8]. This mechanism will be discussed in detail below.

It also is noteworthy that high intensity of heat transfer in the zone of evaporating microlayer may not explain high 
intensity of boiling heat transfer as a whole: the share of heating surface simultaneously covered by the microlayers is quite small. It also is of essential interest peculiarities of heat transfer to evaporating liquid microlayers with low share of heating surface with intensive cooling.

The subject of the analysis [18] is evaporation of a liquid wetting the system of open triangular capillary grooves. The process really represents the case of heat transfer with prevailing role of continuous evaporation of liquid microlayers in the zones of the edges of liquid menisci.

The model of the process is presented in Fig. (3). The problem relates to the sphere of conjugate heat transfer. Taking in account crucial role of concentration of heat flux in the zones of the edges of liquid menisci, the cross section along bottom points of the capillary grooves is accepted as a basic isothermal surface for determination of HTC through analysis and through experiments as well [19].

Corresponding analysis of steady-state heat conduction through combined metal-liquid layer leads to following equation for average HTC during evaporation from triangular capillary grooves:

$h=\frac{1}{\varepsilon} \sqrt{\frac{k_{w} k}{\sin \vartheta \operatorname{tg}(\varphi / 2)}}$

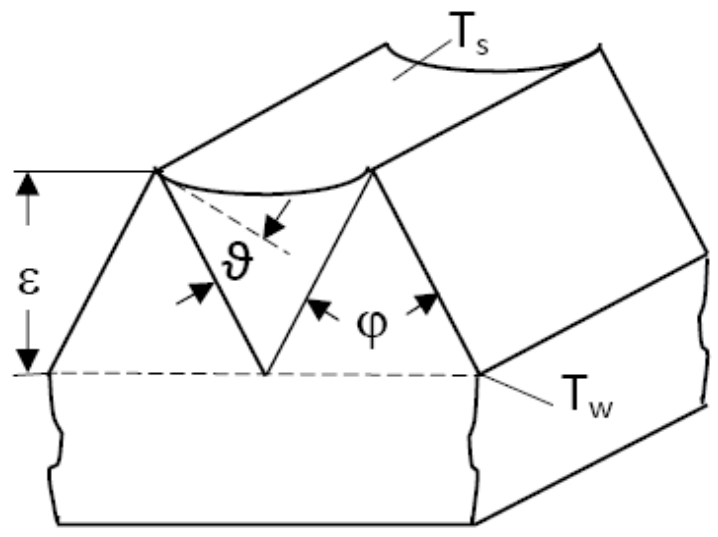

Fig. (3). Model of evaporation on triangular grooves.

Comparison of equation (1) with the experimental data [19] on distilled water evaporation and steam condensation is presented in Fig. (4) (concurrent arrangement of the data on evaporation and condensation reflects the range of heat fluxes with evaporation without nucleation inside grooves).

As it follows from comparison, capability of heating surface to redistribute and concentrate heat flux in the zones of liquid microlayers, in full accordance with equation (1), strongly influences average HTC (with a factor around 5 between stainless steel and copper). Besides, here is presented only the part of wide experimental data [19] confirming equation (1).

In such a manner, HTC strongly depends on thermal parameters and thickness of heating surface in any heat transfer process with prevailing role of evaporation of liquid microlayers covering only small areas distributed on all heating surface.

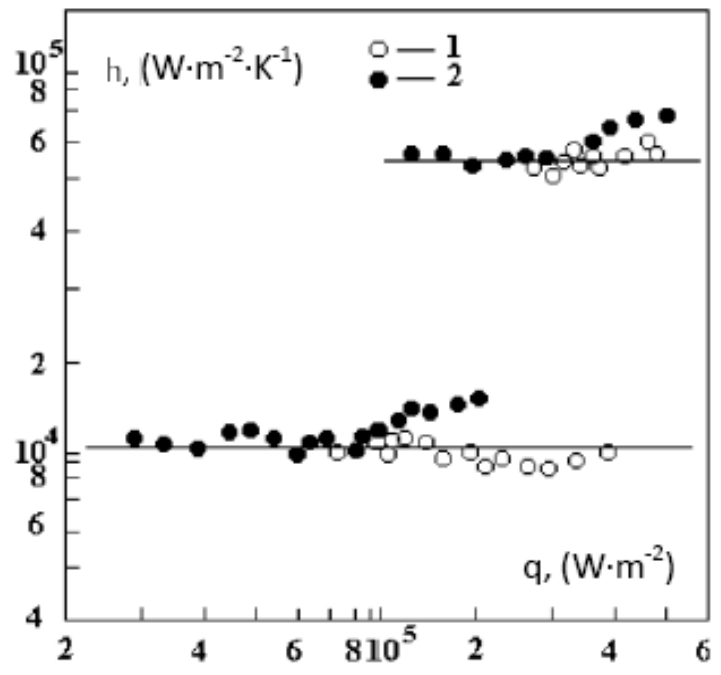

Fig. (4). Comparison of equation (1) (horizontal lines) with experimental data [19] on steam condensation and distilled water evaporation on the surfaces with triangular grooves $(\varepsilon=0.5 \mathrm{~mm})$ made of stainless steel (lower data) and copper (upper data): 1 condensation; 2 - evaporation.

Correspondingly, the fact, that such an influence of heating surface is not observed in the majority of experiments on developed boiling heat transfer, should be considered as evidence of insignificant role of microlayer evaporation mechanism in average heat transfer. Below this important issue is discussed in more detail.

At the same time aforementioned circumstances do not prohibit microlayer evaporation from the role of tangible cooling mechanism. Its contribution is higher at greater shares of contact area of bubbles with heating surface and at comparatively low superheats. In this context, microlayer evaporation may play significant and even leading role in boiling heat transfer at microgravity, at high saturation pressures, on heating surfaces with high-sized nucleation sites and, especially, at transition to prolonged action of the mechanism, for instance, in the microsystems.

\section{Bubbling Mechanism}

Bubbling mechanism is associated with exchange and displacement of liquid and vapor volumes during growth, departure and elevation of vapor bubbles. Bubbling generates complex flow including the stages of pushing the liquid by growing bubble, replacement of detaching bubbles by a liquid, displacement of overheated liquid boundary layer by detached bubble, drift liquid current subsequent to detached bubble (Fig. 5). By tradition this mechanism claims to be the major among boiling heat transfer mechanisms.

At the same time presented in Fig. (2) typical cycle of local temperature variation unambiguously shows that only launched by bubble growth mechanism can play leading role in boiling heat transfer. Assuming that main cooling effect of bubbling takes place consequent to a bubble departure, a conclusion is made about major role of PEGB and second-rate intensity of the bubbling mechanism $[8,20]$.

In [21] the mechanism is studied through bubbling of saturated by hexane inert air through liquid hexane with 
simultaneous registration of local heat transfer during the cycle of air bubble growth, detachment and elevation. The most important outcome is establishment of maximum intensity of heat transfer consequent to detachment of the bubble. The bubble growth and elevation are characterized by low intensity of heat transfer.

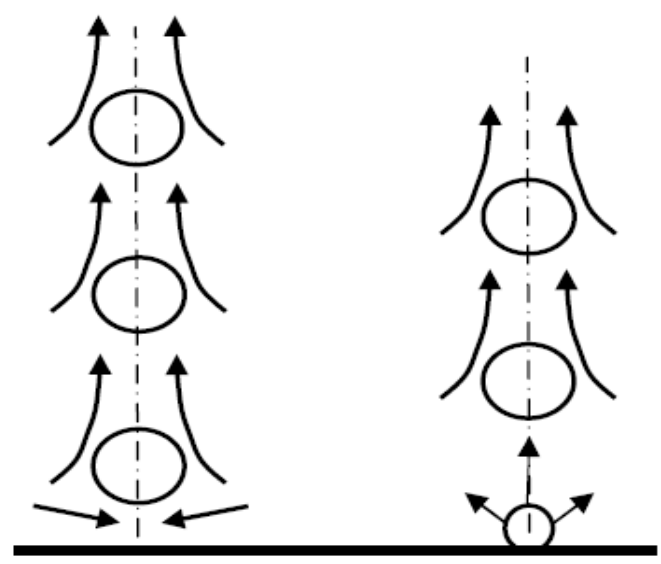

Fig. (5). A scheme of bubbling mechanism.

Insignificancy of the role of bubbling during boiling also is established in experimental study of heat transfer during bubbling of humid nitrogen into water through perforated heating surface [22].

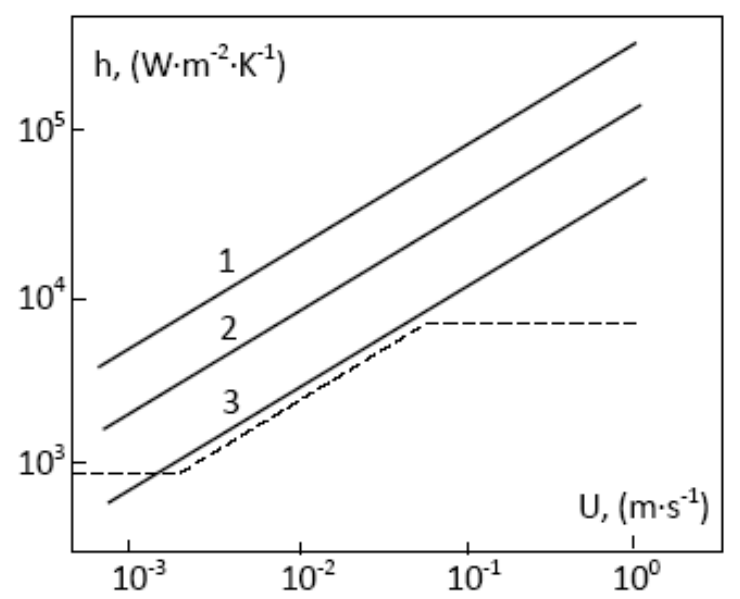

Fig. (6). Comparison of experimental data on HTC during boiling of water and during bubbling of humid nitrogen into water through perforated heating surface [22]: $1-h=3.14 \cdot q^{0.7}$, $\mathrm{q}_{\mathrm{r}} / \mathrm{q}=0.05 ; 2 h=3.14 \cdot q^{0.7}, \mathrm{q}_{\mathrm{r}} / \mathrm{q}=0.2 ; 3-h=3.14 \cdot q^{0.7}, \mathrm{q}_{\mathrm{r}} / \mathrm{q}=1 ;$ dotted curve - smoothed experimental curve of heat transfer during bubbling.

In Fig. (6) typical dependence of HTC on heat flux during boiling of water at atmospheric pressure $(h=$ $3.14 \cdot q^{0.7}$, here $h$ is in $\mathrm{W} \cdot \mathrm{m}^{-2} \cdot \mathrm{K}^{-1} ; q$ is in $\mathrm{W} \cdot \mathrm{m}^{-2}$ ) is transformed into dependence of HTC from vapor generation velocity averaged for the surface at three different values of $\mathrm{q}_{\mathrm{r}} / \mathrm{q}$. The dependence also is presented of HTC during bubbling of humid nitrogen from average normal velocity of nitrogen [22] (humidity of nitrogen is sufficient for practically full prevention of water evaporation from a bubble surface).
As during boiling of water at atmospheric pressure typical values of $\mathrm{q}_{\mathrm{r}} / \mathrm{q}$ are much less 0.2 [6, 15-17], boiling HTC turns out to be 4-5 times higher than the same parameter in corresponding bubbling regime.

Such a result unambiguously shows secondary importance of bubbling mechanism.

It is evident also that made in [22] opposing conclusion about major role of bubbling mechanism in boiling heat transfer suffers from internal inconsistency.

This conclusion is based on experimental data accepted at very high bubbling velocities corresponding to condition of heat removal only through immediate evaporation $\mathrm{q}_{\mathrm{r}} / \mathrm{q}=1$ (to say, to condition of a priori negligible role of bubbling mechanism in boiling heat transfer). Further, the results accepted through such an intensive bubbling are used as an evidence of prevailing role of bubbling mechanism in boiling process with weak vapor flow immediately generated on heating surface.

Aforementioned experiments are valuable also in terms of revelation of insignificant role of thermocapillary Marangoni convection in boiling heat transfer. This aspect of the problem is touched below.

\section{Pumping Effect of Growing Bubble}

PEGB (Fig. 7) [8, 23] is caused by sharp variability, along bubble surface, of transverse momentum transport by evaporation, to say, by sharp variability of a reactive force applied to an interface.

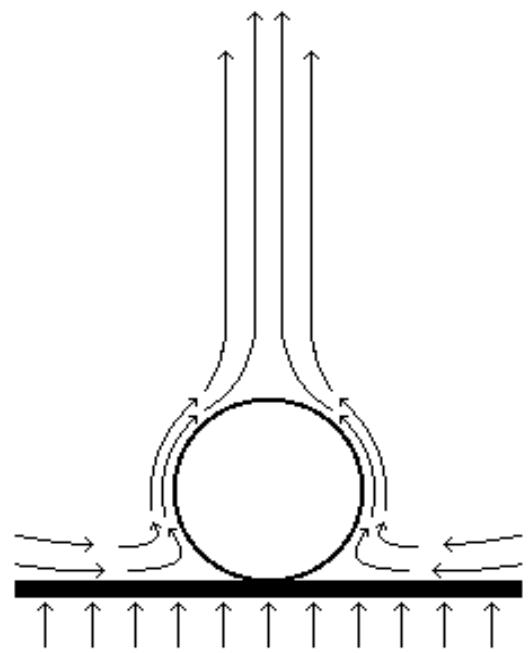

Fig. (7). A model of pumping effect of growing bubble (PEGB).

Generated in such a way superficial pressure gradient covers all thickness of liquid boundary layer (as a volume force) [24] and speeds-up liquid flow along the interface. According $[11,25]$ corresponding acceleration may be at two orders of magnitude above of normal gravity acceleration.

Intensity of PEGB strongly depends on initial superheat of boiling surface. Therefore PEGB is much more intensive at relatively low pressures, small-sized nucleation sites and high surface tension (e.g. in liquid metals). "Switched on" simultaneously with the onset of bubble growth, liquid flow quickly reduces initial gradient of temperature due to that it arises and "cuts off" itself even if a bubble still remains on the wall. 
In such a way PEGB reconciles character of local temperature pulsation with prevailing role of liquid phase convection in the majority of boiling processes.

Decisive role could have been played by thorough interpretation of the results of the experiments [13, 26, 27] in establishment of basic role of PEGB in boiling heat transfer.

Discovery of the phenomenon of bubble departure against the gravity force (Fig. 8) [26] unambiguously evidences high intensity of PEGB.

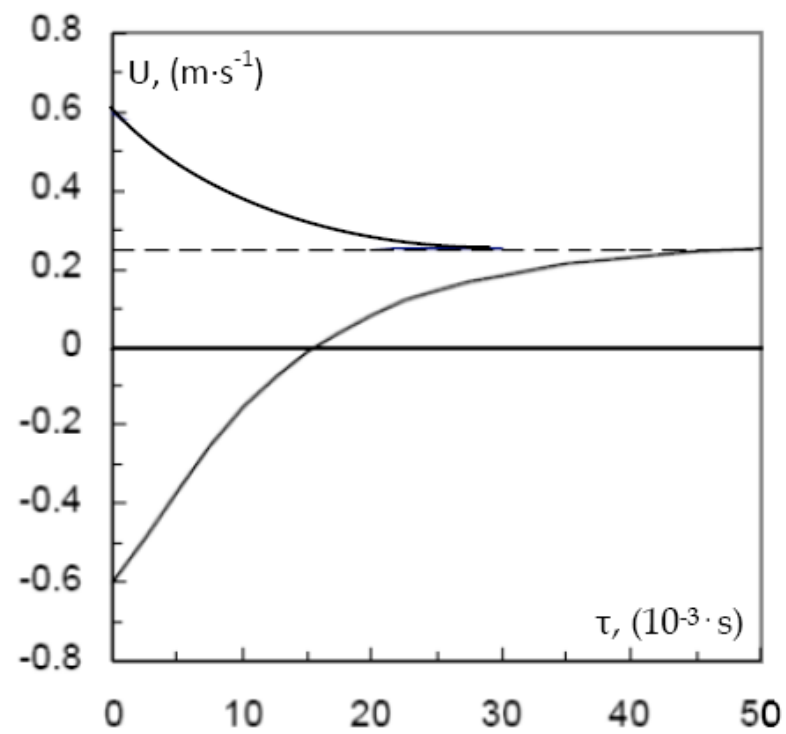

Fig. (8). Vertical velocity of vapor bubble subsequent to departure from thin wire [26]: upper curve - upward departure; bottom curve - downward departure; dotted line - equilibrium elevation velocity; point 0 - departure instant.

Roughly constant velocity of bubble departure is registered during boiling of water on thin horizontal wire (Ø $0.2 \mathrm{~mm}$ ) under atmospheric pressure no matter the departure is oriented. Besides, departure velocity ( $\sim 0.6$ $\mathrm{m} / \mathrm{s})$ is more than twice higher of a bubble equilibrium elevation velocity.

As it is noted in [28-30], low heat capacity of thin wire and its rather low hydraulic resistance to transverse flow result fast transition of the bubble from the role of the accelerator of the liquid jet to the role of the object to be swept out by the same jet continuing by inertia.

As it follows from Fig. (9), growing bubble speeds-up jet flow directed transversely to thin wire at the stage a. In connection with low heat capacity of thin wire speeded-up liquid flow rapidly eliminates superheat serving as energy source for PEGB. Accordingly, the bubble stops pumping liquid when it still has very small diameter. Further liquid flow continues by inertia and sweeps the bubble from the wire (the stage b).

Significant role is played here by very small value of the gravity force applied to the bubble. As this force is proportional to third order of bubble diameter, small departure size of the bubble makes the gravity force extremely weak. Therefore, dynamical force wins this concrete opposition. a

b

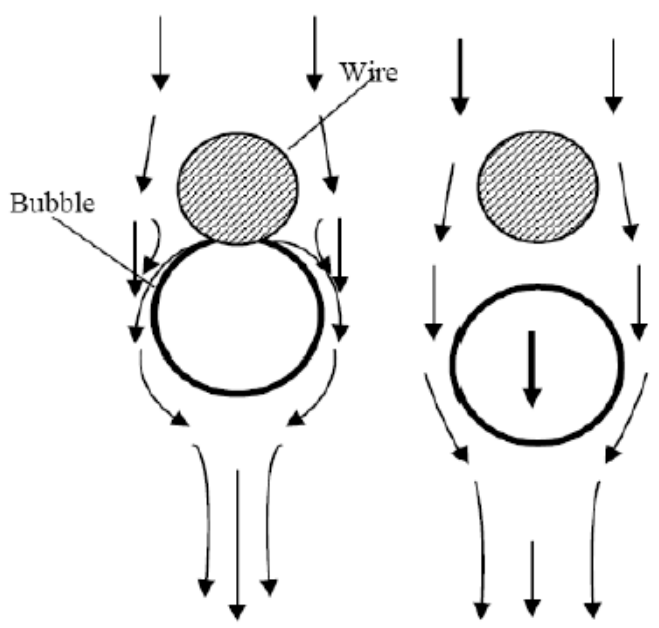

Fig. (9). A scheme of bubble departure from thin wire against the gravity force.

At the same time, as liquid flow velocity markedly reduces to the stage $b$, bubble departure against gravity force with velocity $0.6 \mathrm{~m} / \mathrm{s}$ evidences speeding-up of much more strong flow at the stage a.

Unfortunately, in [26], observed phenomenon is not identified as a manifestation of PEGB (as an evidence of speed-up of strong liquid jet flow at initial stage of bubble growth). In unison, the authors have not fixed foregoing bubble departure liquid jet flows later clearly observed in just the same conditions [31].

In fact high intensity of PEGB directly is fixed in experiments [27] on boiling of water at atmospheric pressure. At that liquid removal velocity from the top of growing bubble is higher than $2 \mathrm{~m} / \mathrm{s}$ (Fig. 10).

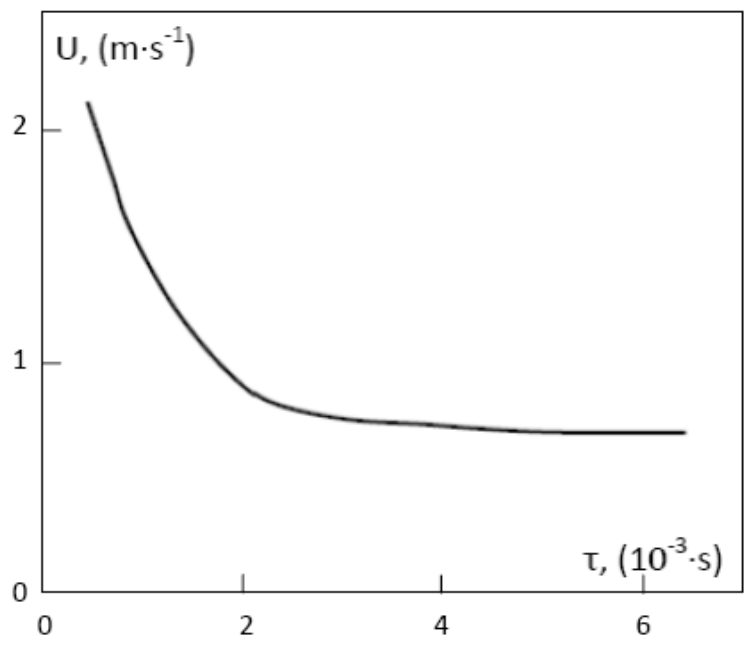

Fig. (10). Vertical velocity of superheated liquid from the top of growing bubble [27].

Unfortunately, most likely in connection with accidental arithmetic errors, these important data are interpreted as temperature wave propagation through stationary fluid by thermal conductivity (registered velocities are at two-three orders of magnitude higher than possible velocities of such a propagation). 
Impressive evidences of insignificancy of the role of microlayer evaporation in local temperature pulsations and extremely high intensity of PEGB are presented in [13].

As it follows from this experiment [13], temperature pulsations of massive ( $\varnothing 60 \mathrm{~mm}$ ) copper substrate penetrate to a depth more than $30 \mathrm{~mm}$. In addition, liquid jets, speeded-up by growing bubbles up to velocity $5 \mathrm{~m} / \mathrm{s}$, are picked up on the film (Fig. 11).
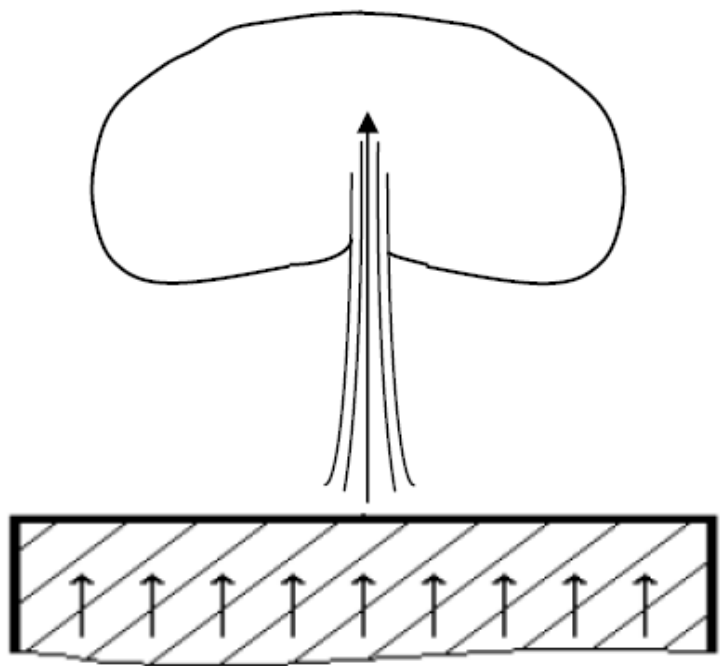

Fig. (11). Speeded-up liquid jet flow $(5 \mathrm{~m} / \mathrm{s})$ penetrating through full-grown large preceding vapor bubble [13].

According simple calculations, the heat released from the substrate turned out to be at around two orders of magnitude above that expended for forming a bubble of departure size. Unfortunately, the authors lose an opportunity to demonstrate insignificancy of the role of microlayer evaporation in such a simple way. The authors also desist from any comments regarding strong manifestation of PEGB in the form of extremely strong jet flows. Leaving aside similar strong factual evidences of dominant role of PEGB, they attempt to link received experimental data to leading role of microlayer evaporation.

Effect of ejection of liquid metal with velocity 100-150 $\mathrm{m} / \mathrm{s}$ is discovered during laser drilling of nickel and copper [32]. Although the effect is linked to PEGB (to vapor bubble nucleation), this specific phenomenon requires further investigation.

Real steps toward deep and systematic study of PEGB during boiling on thin wires firstly are made in works [31, 33-34].

Various rather powerful manifestations of PEGB are observed and recorded, including phenomenon of vapor bubble departure against gravity field. Experimental investigations are performed of diverse dynamical effects including bubble specific motion on microwires. Nongravity character of the observed phenomena is confirmed. Numerical model of bubble motion and adjacent jet flows through subcooled boiling on microwires is developed.

It presents particular interest discovery of so-called multi-jet flow (in addition to single jet-flow) that calls for undertaking of certain refinement of the previous scheme of PEGB (Fig. 7).

As it follows from additional analysis, together with the previous basic case, another limiting case of realization of PEGB should be considered.

Initial bubble growth takes place within high initial temperature gradient in liquid boundary layer. In this connection driving pressure gradient is effective on all surface of the bubble. In addition, an angle between heating wall and bubble surface still remains sufficiently large for development of two-dimensional liquid flow. These circumstances result speeding-up of individual jet flow from the top of the bubble, in full accordance to the previous scheme (Fig. 7).

Further liquid flow evolves to another limiting case when abovementioned angle becomes too small for preservation of two-dimensional flow. Concurrently, driving gradient turns out to be concentrated only on the bottom part of the bubble surface (on interface gap between the bubble and heating wall). Liquid flow in the gap becomes three-dimensional (with alternation of the zones of liquid suction and rejection) and PEGB evolves into multi-jet flow.

It can be also assumed that certain intermediate schemes of liquid flow can be realized between the limiting cases mentioned.

The phenomenon of multi-jet flow also presents interest in the context of possible contribution of Marangoni flow in observed phenomena [35].

As distinct to PEGB, Marangoni flow is driven by surface force generated by gradient of surface tension on interface with variable temperature. However, in the case of single jet flow in symmetric bubble-surface system, both of flow schemes are roughly similar.

During boiling of saturated water directly measured and indirectly evaluated jet flow velocities vary in the range 1-5 $\mathrm{m} / \mathrm{s}$ [13, 27, 31]. According review of experimental data [36] maximum velocities of steady-state (needing minimum driving force) Marangoni flow are at around 2 orders of magnitude less of aforementioned values.

Taking in account that temperature gradients are near to zero on bubble surface during saturated boiling, the conclusion should be made that observed jet flows turn out to be extremely strong to be explained by Marangoni effect. The same conclusion follows from analysis [11-25] showing much greater role of the pressure gradient caused by momentum transport by evaporation in comparison with thermocapillarity.

During boiling of subcooled liquid jet flows are much weaker (characteristic velocities $15-150 \mathrm{~mm} / \mathrm{s}$ ) [33]. Velocities of bubble slippage are in the range $15-40 \mathrm{~mm} / \mathrm{s}$.

Contribution of Marangoni effect evidently may be tangible at such a low velocities. Nevertheless, interpretation of dynamical effects $[33,34]$ by the steady-state thermocapillary Marangoni flow model [37] should be subjected to careful approach [38].

There are two potential sources of overestimation of Marangoni flow velocities: using of very small value of accommodation coefficient (0.03) and consideration of steadystate flow. According [39] accommodation coefficient is near 
to unity on liquid-vapor interface. However, phase conversion may be affected by presence of non-condensable air [37].

Nevertheless, absence of concrete substantiation of accepted value makes its accuracy questionable. The more so as no consideration is made of the concentration of noncondensable air on the condensation side of the bubble interface (this circumstance evidently results overestimation of intensity of Marangoni flow along evaporation zone).

The last conclusion especially concerns multi-jet flow (so-called butterfly-like structure) [34] that just is developed along the zone of evaporation (Fig. 12).

During boiling the zone of maximum surface tension clearly is linked to the top of a bubble.

Besides, Marangoni flow-out always is directed transversely from the zone of maximum surface tension. These circumstances call into principal question possibility of speeding-up by Marangoni effect of multi-jet flow at a tangent to bottom zone of a bubble. In this connection, one may realistically assume that launching of multi-jet flow from bottom zone of a bubble evidences prevailing role of PEGB.

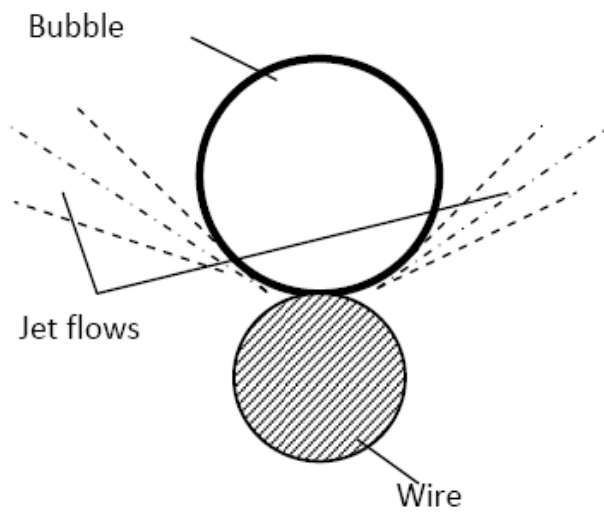

Fig. (12). Multi-jet flow during boiling of subcooled liquid on microwire [34].

Concerning the role of Marangoni flow important conclusions could have been done based at aforementioned experiments on bubbling [21, 22]. As bubbling of humid air proceeds without tangible evaporation, temperature drop on bubble surface before departure practically is equal to temperature drop between heating surface and bulk liquid.

In contrast to it, during boiling, temperature at bubble surface practically is equal to saturation temperature corresponding to the pressure in bubble itself. Only some superheat of bubble surface takes place in the zone of microlayer adjacent to heating surface. Corresponding variation of temperature along the surface of vapor bubble is small and may achieve maximum several percent of temperature drop between boiling surface and saturated bulk water.

In this connection, if variation of bubble surface temperature may be of order $10 \mathrm{~K}$ during bubbling, such a variation may achieve only $0.1-0.2 \mathrm{~K}$ at the same heat flux during boiling.

In such a manner, thermocapillary driving force is at around two orders of magnitude stronger during bubbling in comparison with comparable boiling process. In this connection fixed low intensity of heat transfer during air bubble growth [21] and low average HTCs during bubbling through perforated surface [22] demonstrate insignificancy of Marangoni convection in boiling heat transfer.

It also presents significant interest the role of PEGB in forced convection boiling in the microsystems. This aspect of the problem is discussed below.

Finalizing the subchapter let us discuss potential influence of PEGB on critical heat flux (CHF).

As it is known, CHF depends on intensity of mechanisms responsible for vapor phase removal from heating surface. Hydrodynamic theory of boiling crisis [40], assuming basic role of the gravity field in vapor phase removal, quite adequately describes experimental data on CHF during pool boiling of ordinary liquids.

At the same time, there is some part of pool boiling processes characterized by significantly higher values of $\mathrm{CHF}$ in comparison with predicted by the hydrodynamic theory.

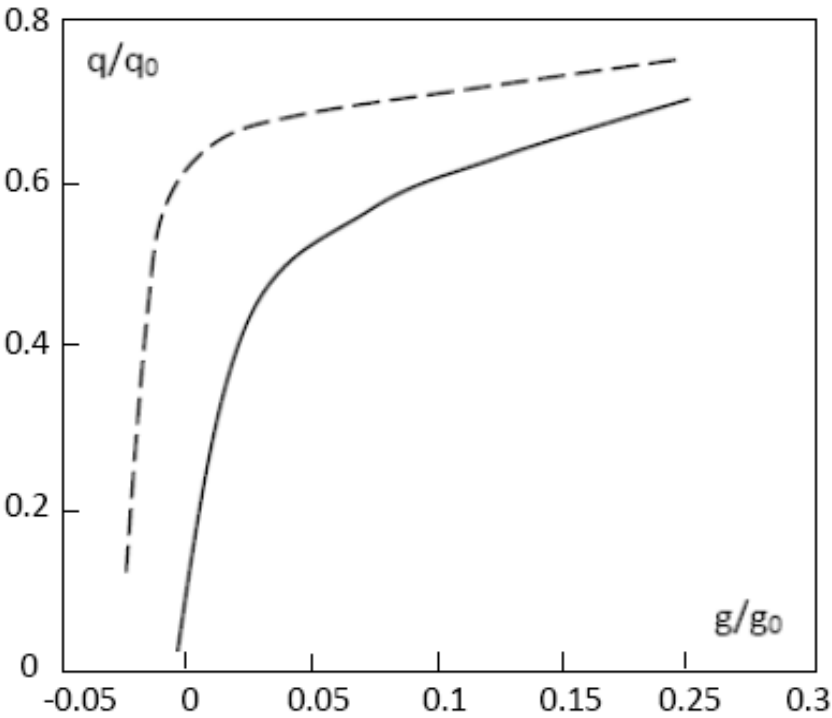

Fig. (13). Smoothed experimental curve on CHF during pool boiling of water, nitrogen and hydrogen under reduced gravity acceleration dashed line [41]; Solid curve - according hydrodynamic theory of crisis [40].

In particular, such a lead is established during boiling of water, nitrogen, hydrogen [41] (Fig. 13), n-pentane, CFC and other liquids $[42,43]$ in microgravity, during pool boiling of liquid metals [44] (Fig. 14), during pool boiling of organic liquids and water under vacuum [45] (Fig. 15).

In such a manner experimental $\mathrm{CHFs}$ precede theoretical ones at $300-500 \%$. Similar result can be considered as an evidence of existence of certain rather strong nongravity mechanism of vapour phase removal from heating surface. As microgravity and low saturation pressure just are favourable for PEGB, it is supposed that just PEGB is responsible for 
high values of CHF [28, 29]. However, this aspect of boiling problem needs further detailed investigation.

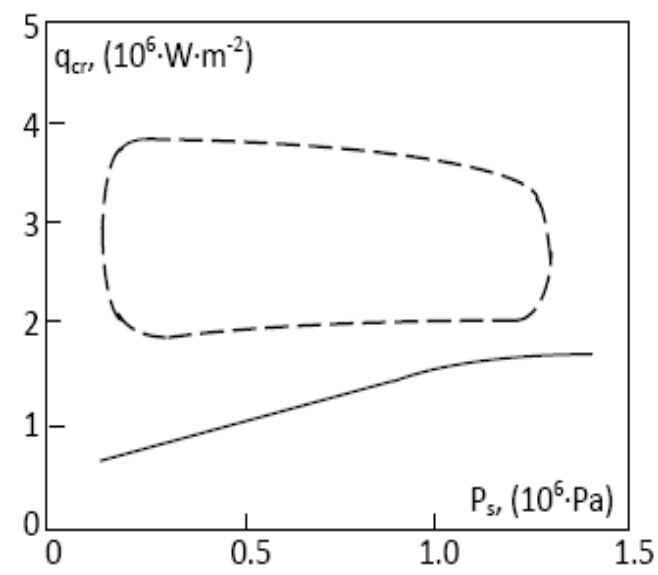

Fig. (14). Experimental data [44] on CHF during pool boiling of sodium (dotted loop); bottom curve - according hydrodynamic theory of crisis [40].

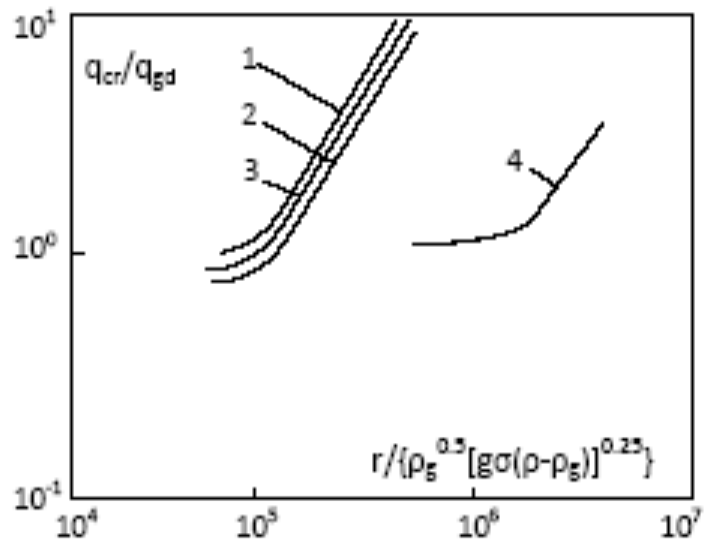

Fig. (15). Smoothed experimental curves [45] on CHF during pool boiling of dautherm-A (1), chlorbenzene (2), toluene (3), and water (4) at reduced saturation pressures; $\mathrm{q} / \mathrm{q}_{\mathrm{gd}}=10^{0}-$ according hydrodynamic theory of crisis [40].

\section{Micro-membrane Pumping Effect}

It also presents certain interest specific convective cooling mechanism linked to permanent vibration of nuclei in all potential sites, synchronously with local pulsation of heating surface temperature [11]. Such a cooling mechanism may be named as micro-membrane pumping effect (MMP).

While local temperature increases, nucleus surface (a micro-membrane) expands to critical profile, stops expansion when the nearest nuclei starts growth into the bubble with PEGB and returns to previous position when local temperature drops. Besides, in connection with quick drop of local temperature, contraction of the micro-membrane is much quicker than its expansion. Correspondingly, downward motion of the micro-membrane is much faster. The last circumstance, together with almost ideal distribution of such downward flows on heating surface, on huge number of potential sites (up to $10^{3} \mathrm{~cm}^{-2}$ ), presents important feature of MMP.
In such a manner, MMP also presents dynamical effect of nongravity nature main cooling action of which also is triggered by onset of bubble growth.

Velocity of downward motion of the micro-membrane depends on effective radius of nucleation site and on the time of local temperature drop. According preliminary evaluations, in characteristic regimes of boiling heat transfer, such a velocity may vary in rather wide range from $0.5 \mathrm{~mm} \cdot \mathrm{s}^{-1}$ to 20 $\mathrm{mm} \cdot \mathrm{s}^{-1}$. In contrast to PEGB, cooling effect of MMP may not claim to be dominant. However, the effect deserves to be studied analytically and experimentally.

\section{A Slope of Boiling Heat Transfer Curve}

A slope of boiling heat transfer curve in coordinates $q \sim h$ or $\Delta T \sim q$ (determined by an exponent in equations of the type $h \sim q^{n}$ or $\left.q \sim \Delta T_{s}^{m}\right)$ varies in rather wide range $(n=0.5-0.9)$. In the case of commercial heating surfaces this range is narrower $(n=0.65-0.75)$.

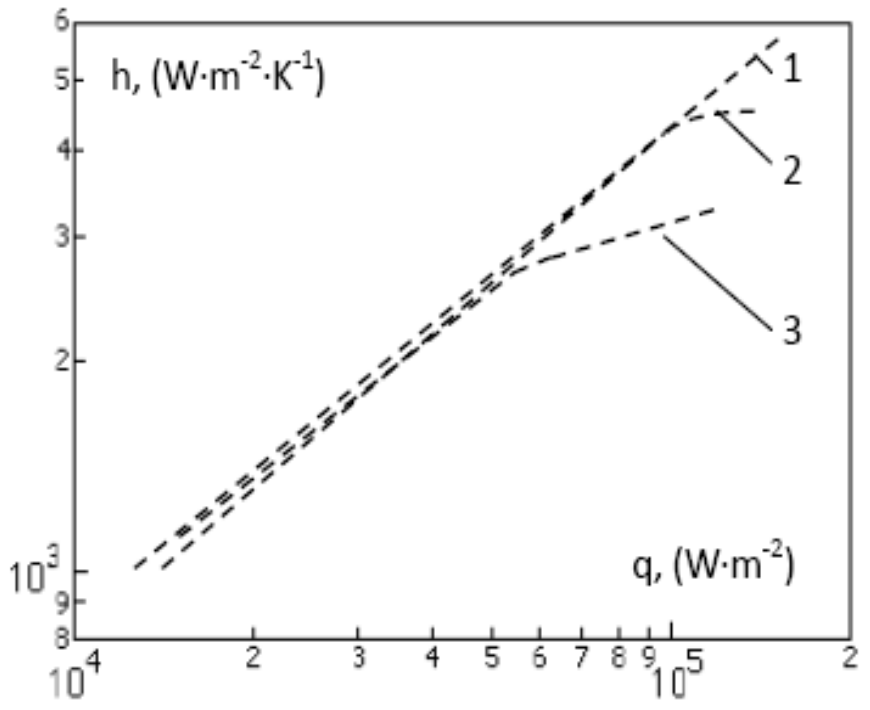

Fig. (16). Smoothed experimental curves on HTC during developed boiling of benzene at atmospheric pressure on heating surfaces with different densities of uniform big nucleation sites [46]: 1 - N/A $=4 \cdot 10^{6} \mathrm{~m}^{-2} ; 2-\mathrm{N} / \mathrm{A}=1 \cdot 10^{6} \mathrm{~m}^{-2} ; 3-\mathrm{N} / \mathrm{A}=0.25 \cdot 10^{6} \mathrm{~m}^{-2}$.

The problem of the slope of boiling curve in certain degree is clarified in experiments [46] on boiling on heating surfaces with deferent densities of artificially created big uniform nucleation sites (Fig. 16).

As it follows from the experimental data, at sufficient density of nucleation sites, all boiling curve equally corresponds to developed boiling with typical slope $h \sim q^{0.7}$ covered in full range by the surface with $\mathrm{N} / \mathrm{A}=4 \cdot 10^{6} \mathrm{~m}^{-2}$ (case 1). In this case increase of heat flux evidently leads only to "switching on" of additional artificial sites with the same effective radius.

At the same time, if all artificial sites already are "switched on", further increase of heat flux may put in operation only natural sites of the basic surface. On the other hand, as activation of natural sites requires significantly higher superheat, increase of heat flux should be accompanied by tangible deviation of boiling heat transfer curve from the previous slope. 
Presented data unambiguously reflect dependence of the slope of boiling curve on density and sizes of nucleation sites. Typical for majority of experiments slope turns out to be linked to heating surface with great number of nucleation sites with roughly uniform effective radius*.

Presented conclusions are supported by important experimental data [47] on sizes and distribution of operating natural nucleation sites studied through immediate optical observation of boiling process on heating surfaces with different finish classes (with standard roughness parameter $R_{p}$ from 0.1 to $0.4 \mu \mathrm{m}$ ).

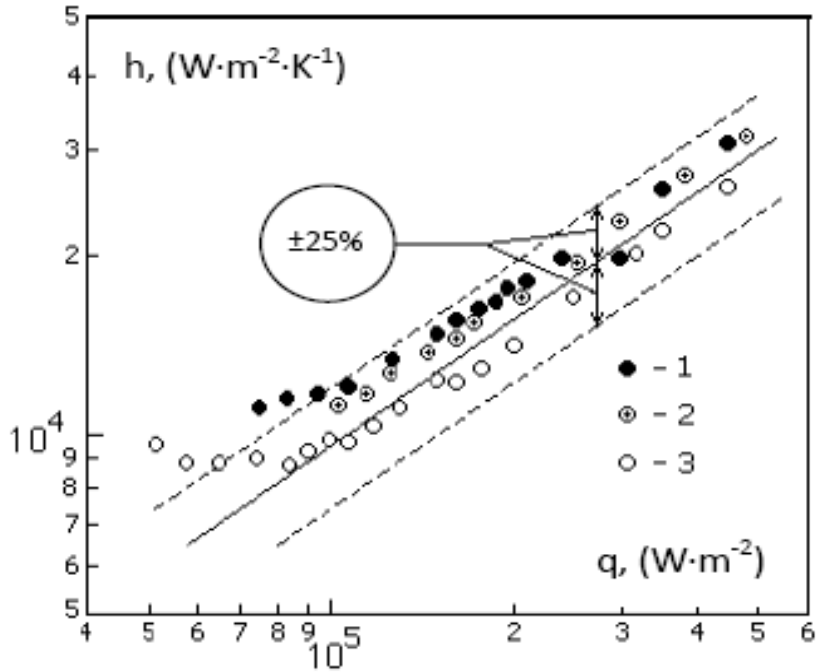

Fig. (17). Heat transfer during developed boiling of water at atmospheric pressure on heating surfaces with different finish classes [47] $\left(1-\mathrm{R}_{\mathrm{p}}=0.4 \mu \mathrm{m} ; 2-\mathrm{R}_{\mathrm{p}}=0.125 \mu \mathrm{m} ; 3-\mathrm{R}_{\mathrm{p}}=0.1 \mu \mathrm{m}\right)$.

According Fig. (17), despite fourfold variation of the standard roughness parameter, the experimental data correspond to known empirical equation for boiling heat transfer of water on commercial surfaces at atmospheric pressure $\left(h=3,14 \cdot q^{0.7}\right)$ within usual accuracy of measurement of boiling HTC.

Distribution of effective sizes of operating nucleation sites also shows insignificant stratification with surface finish classes. Besides, nucleation sites are almost at two orders of magnitude bigger than the standard roughness parameter (Fig. 18).

Observed radii of nucleation sites vary within rather narrow limits from 3 to $10 \mu \mathrm{m}$ (with comparatively great share of small sites) revealing absence of immediate linkage to standard roughness parameter. In certain approximation the value $5 \mu \mathrm{m}$ can be accepted as average radius of nucleation sites. It also should stressed that practical independence of HTC on the standard roughness parameter during its fourfold variation demonstrates principal problems with using of similar parameter for evaluation of the role of heating surface in boiling heat transfer.

*As it was established later, the procedure of determination of effective radius of conical artificial site [46] has led to roughly fourfold overestimation of this parameter. However, this disadvantage had no influence on uniformity of artificial sites.

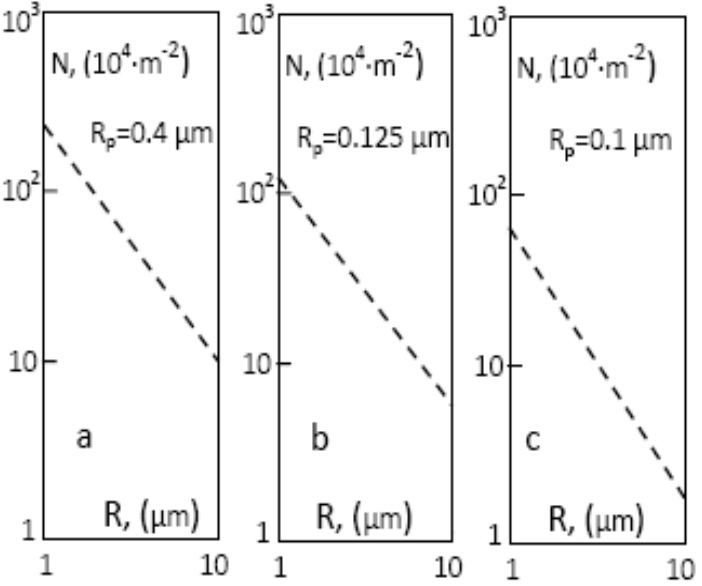

Fig. (18). Smoothed experimental distributions of radii of nucleation sites at different heat fluxes on surfaces with different finish classes [47]: a: $\mathrm{q}=1.67 \cdot 10^{5} \mathrm{Wm}^{-2} ; \mathrm{q}=1.2 \cdot 10^{5} \mathrm{Wm}^{-2} ; \mathrm{q}=0.89 \cdot 10^{5} \mathrm{Wm}^{-2} ; \mathbf{b}: \mathrm{q}$ $=1.2 \cdot 10^{5} \mathrm{Wm}^{-2} ; \mathrm{q}=1.13 \cdot 10^{5} \mathrm{Wm}^{-2} ; \mathrm{q}=0.93 \cdot 10^{5} \mathrm{Wm}^{-2} ; \mathbf{c}: \mathrm{q}=1.31 \cdot 10^{5}$ $\mathrm{Wm}^{-2} ; \mathrm{q}=1.14 \cdot 10^{5} \mathrm{Wm}^{-2} ; \mathrm{q}=0.92 \cdot 10^{5} \mathrm{Wm}^{-2}$.

In this context these results fully confirm the model [20] linking HTC to average effective radius of nucleation sites. This aspect of the problem is discussed below. At the same time coincidence of experimental data on HTC with known data on developed boiling of water on commercial surfaces supports the previous assumption [20] about rough equality of average effective radius of nucleation sites of commercial surfaces to $5 \mu \mathrm{m}$.

\section{Two Basic Features of Developed Boiling Heat Transfer}

According our analysis the most important features of developed boiling heat transfer are the following:

- Independence of superheat of heating surface on intensities of separate cooling mechanisms;

- Simultaneous triggering by the onset of a vapor bubble growth of the main cooling mechanisms (by liquid phase convection and microlayer evaporation).

Experimental fundamentals of such a conclusion are discussed below.

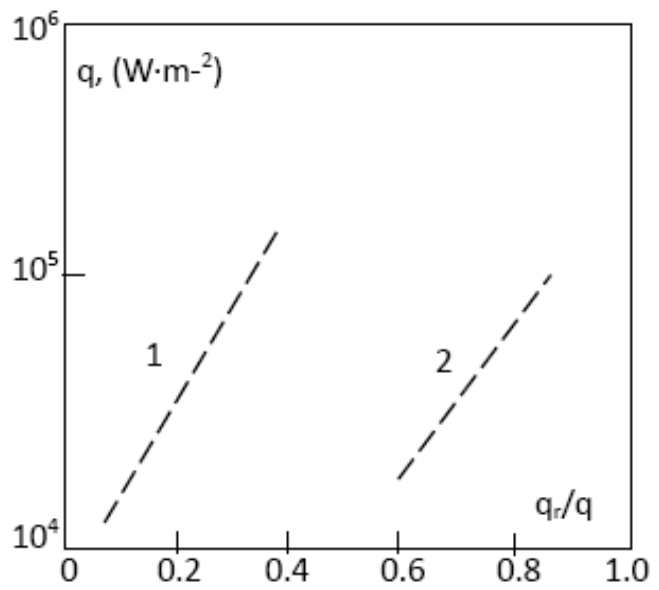

Fig. (19). Contribution of immediate evaporation and liquid phase convection mechanisms with variation of acceleration of a body force according smoothed experimental curves [48]: $1-\mathrm{g} / \mathrm{g}_{0}=1 ; 2-\mathrm{g} / \mathrm{g}_{0}=$ 0.03-0.04. 
Presented in Fig. (19) experimental data [48] reflect qualitative redistribution of the shares of immediate evaporation and liquid phase convection cooling mechanisms with variation of intensity of a body force. In particular, evaporation mechanism, playing secondary role at normal gravity, gains leading role with reduction of $\mathrm{g}$ around 20 times.

In contrast to it, presented in Fig. (20) experimental data [49]) reflect independence of HTC from variation of intensity of body force at around four orders of magnitude. Similar results are received also in [50-52] carried out in the range of variation of mass acceleration from $10^{-6} \mathrm{~g}_{0}$ to $5 \cdot 10^{3} \mathrm{~g}_{0}$ (almost 10 orders of magnitude).

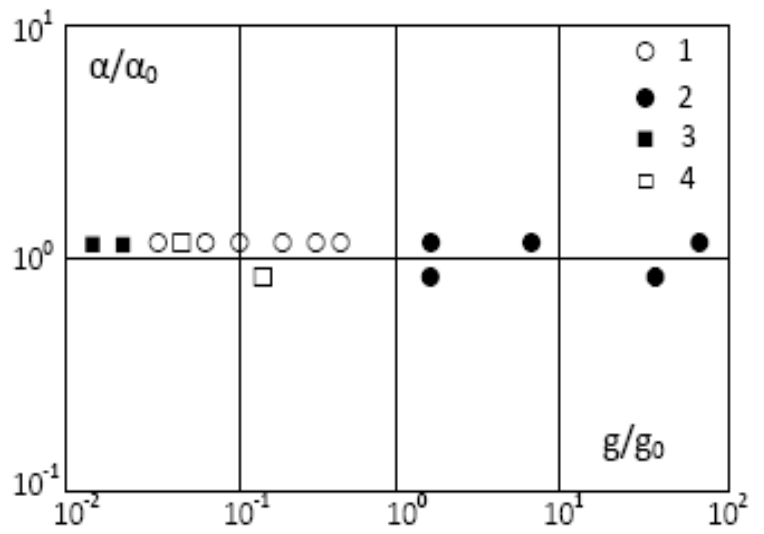

Fig. (20). Boiling HTC under different intensities of a gravity force normalized to normal gravity condition [49]: 1 - oxygen; 2 - water; 3 - ethanol; 4 - ethyl ether.

Presented in Fig. (21) scattering range of experimental data [52] reflects independence of HTC during boiling of CF-72 on small heaters on variation of acceleration of body force in the range $0.02 \mathrm{~g}_{0}-1.8 \mathrm{~g}_{0}$ and on variation of subcooling of a liquid in the range $7 \mathrm{~K}-34 \mathrm{~K}$.

Presented in Fig. (22) heat transfer curves reflect regularities of forced convection boiling on horizontal tube in the conditions of crossflow of slightly subcooled R113 [53].

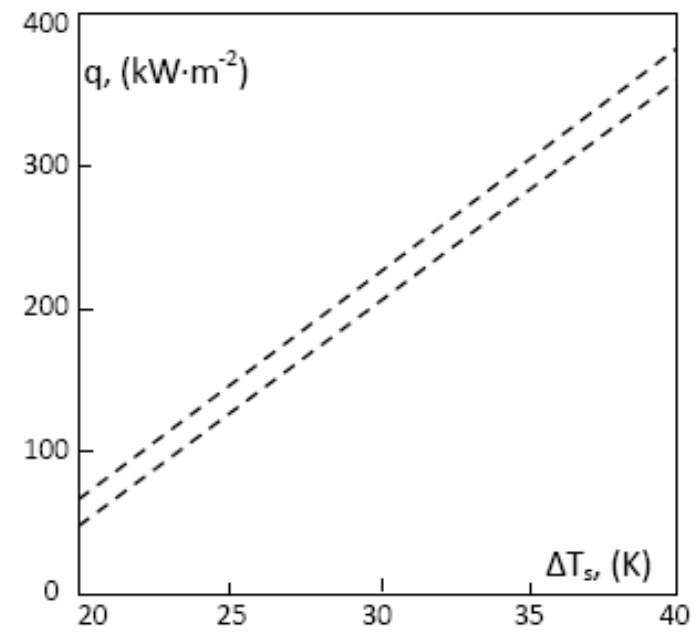

Fig. (21). Scattering range of HTC during pool boiling of CF-72 on small heaters under subcooling (in the range 7-34 $\mathrm{K}$ ) and different gravity accelerations (in the range $0.02 \cdot \mathrm{g}_{0}-1.8 \cdot \mathrm{g}_{0}$ ) [52].
Forced convection heat transfer curve always comes together with developed pool boiling curve with the climb of heat flux. At that crossflow velocity $(0.03-0.235 \mathrm{~m} / \mathrm{s})$ and the degree of subcooling $(6 \mathrm{~K})$ influence only parameters of merger of the forced convection boiling curve with the developed boiling curve. The same conclusion is made in generalized description of forced convection boiling in [54].

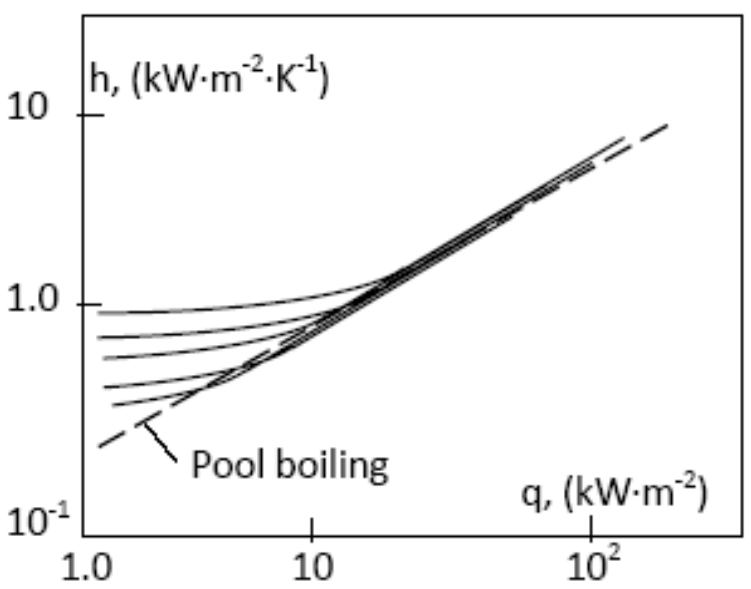

Fig. (22). Smoothed experimental curves on forced crossflow boiling on horizontal tube of slightly subcooled R113 [53]: upper curves correspond to higher crossflow velocities.

Experimental data on influence of orientation of heating surface in the gravity field on boiling heat transfer of water [55] are presented in Fig. (23).

As it follows from presented data developed boiling mode is conservative regarding to this type of influence as well. Similar results are received also in detailed study [56] (in this work, corresponding figures are plotted using HTC determined through $\Delta \mathrm{T}$ ).

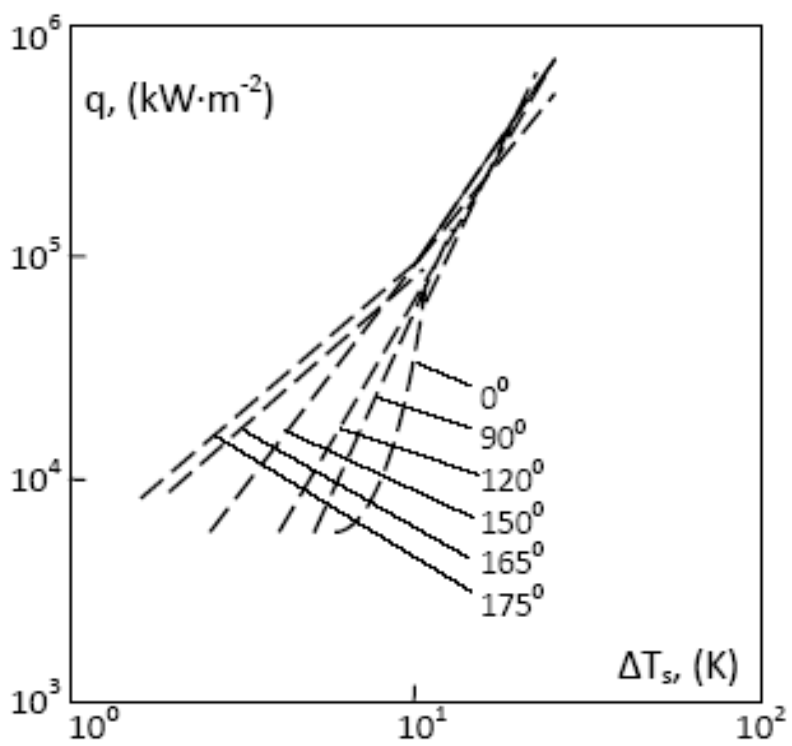

Fig. (23). Influence of inclination of heating surface on boiling heat transfer of water at atmospheric pressure. (smoothed experimental curves) [55].

The same conservatism of developed boiling heat transfer law manifests itself in the part of experiments on flow boiling 
in minichannels and microchannels. However, the results of some similar experiments show qualitatively differing trends. In this context it also presents significant interest coincidence of experimental curves on boiling of water on massive copper surface [47] and on thin platinum wire with diameter $0.3 \mathrm{~mm}$ [57] at atmospheric pressure.

Discussed above peculiarities of boiling on thin wires allow to conclude that these two processes are characterized by qualitatively differing inter-phase hydrodynamics. If in the case of massive horizontal copper surface gravity force is main driver of two-phase flow, in the case of thin wire leading role in vapor removal from heating surface is gained by nongravity dynamical effects. Despite such a drastic dissimilarity of these boiling regimes, unified developed boiling heat transfer law equally remains in force in the both cases.

In such a manner, changes in the pattern of mutual motion of the phases, in the numbers of operating sites and in the bubble departure diameters and frequencies, occurring with a change in the intensity of body force by several orders of magnitude, with change of orientation of heating surface in the gravity field, with forced convection and subcooling of bulk liquid, with drastic change of heating surface sizes, all of these conditions have virtually no influence on heating surface superheat in the mode of developed boiling.

According to our analysis this fundamental fact may be interpreted only assuming existence of certain physical mechanism that controls developed boiling heat transfer through multiple triggering of short-run actions of different heat removal mechanisms and holds certain integral cooling effect irrespective to the rates of these mechanisms.

The next in importance basic feature of developed boiling heat transfer is simultaneous triggering of the both liquid phase convection (PEGB) and microlayer evaporation mechanisms by the onset of vapor bubble growth. Although the same onset also triggers another cooling mechanism (MMP), in connection with a lack of detailed information, we shell keep it in store for the time being.

The onset of bubble growth itself is triggered by overcoming by average temperature of the meniscus of critical-size nucleus the level corresponding to thermodynamic equilibrium in the system: nucleus-liquidsite. Consequently, the process of establishment of corresponding superheat of heating surface just presents the mechanism that controls intensity of developed boiling heat transfer.

\section{MTA AND MTD}

Beginning from Jakob [6], Kruzhilin [58] and Rohsenow [59] and further [60-73] main line of development of boiling heat transfer theory is based at approaches connecting HTC to intensity of certain cooling mechanism (an actor) or certain combination of different cooling mechanisms (actors). In this connection these approaches are subsumed under the category dubbed as a model of "the theatre of actors" (MTA). Besides, approaches based at qualitative and dimensional analysis linked to concrete mechanisms also are prescribed to this category.

\section{Principal Restrictions of MTA}

MTA presents efficient universally adopted way of analysis in convection heat transfer theory. However, developed boiling heat transfer manifests exceptionally specific sequence of causes and effects.

In the framework of MTA heating surface superheat is determined by intensity of cooling mechanisms. Really maximum local superheat is found to be determined by thermodynamic conditions at transition of a nucleus through critical size at the onset of bubble growth.

In the framework of MTA so-called internal characteristics of boiling (densities of operating sites and bubble departure diameters and frequencies) naturally become main instrument for determining of temperature regime. In real situation combination of these parameters also turns out to be controlled by thermodynamic conditions at nucleation sites in correspondence with temperature regime to be hold.

Evident contradiction of MTA with the aforementioned basic feature of developed boiling heat transfer calls into principal question efficiency of MTA in terms of establishment of boiling heat transfer law.

According [1-2], among numerous MTA-based correlations, two correlations can be regarded as more accurate. Besides, these correlations fit to boiling HTC data (except liquid metals and cryogenic liquids) using different constants and powers for different surface-liquid combinations. The review [3] regards as the most comprehensive a correlation [67] dividing liquids into four groups (liquid metals once again remain outside of correlation).

At the same time reviews [1-3] fail to discuss a correlation [20, 28-29, 74-76] describing wide experimental data on developed boiling of all groups of liquids, including liquid metals, without dividing of liquids into groups and without matching different constants and powers to different surfaceliquid combinations.

Given in reviews [1-3] evaluations of advances of MTA quite clearly demonstrate existence of theoretical deadlock. However, in this context, it presents certain interest discussion of some concrete disadvantages of MTA.

As bubbling and microlayer evaporation directly are linked to buoyancy driven convection in two-phase area, it is hardly achievable in the framework of MTA to get free in correct way from influence of body force on HTC. This conclusion especially concerns the models introducing vertically driven two-phase structures as the basis for analysis of boiling heat transfer [59, 63-65, 67, 70-72].

If HTC is determined by interactions on boundaries and inside such a structures, it is hardly explicable why heating surface superheat during developed boiling remains unchangeable through essential transformation or even with full disappearance of these structures (for instance, through change of gravity acceleration at several orders of magnitude or under deep subcooling). 
The problem of adequate reflection of the role of gravity field also remains pressing in the case of qualitative dimensional considerations.

For instance, aforementioned correlations for four groups of liquids [67] are developed through regression analysis applied to numerous data points on HTC. The analysis starts from more than 10 dimensionless numbers obtained in the framework of MTA. Finally the following dependences of HTC on gravity acceleration are obtained for separate groups of liquids:

$h \approx g^{0.483}$ (for water)

$h \approx g^{-0.085}$ (for hydrocarbons)

$h \approx g^{-0.515}$ (for cryogens)

$h \approx g^{0.033}$ (for refrigerants)

Similar qualitatively differing dependences hardly allow to considering abovementioned approach as linked to physics of studied phenomenon.

Principal disadvantage of microlayer evaporation version of MTA is connected with contradiction between independence of HTC on thermal parameters of heating surface during developed boiling and aforementioned conclusion about significant influence of thermal conductivity of heating surface on average HTC during microlayer evaporation (by the way, this conclusion is supported by numerical MTA-based models of boiling heat transfer [70, 73]) developed based at assumption on leading role of micro and macrolayer evaporation mechanisms.

In general, comprehensive approach to boiling heat transfer problem should allow to interpreting independence of HTC on thermal parameters of heating surface during developed boiling and reality of influence of the same parameters in some other regimes. The same conclusion concerns the phenomenon of boiling heat transfer hysteresis that also is observed only in the part of experiments. No MTA-based approach meets these challenges.

Another disadvantage of MTA is connected with principal difficulties with incorporation of characteristic linear size of nucleation sites. In this connection MTA turns to be incapable to make use of wide investigations in the physics of nucleation.

As average effective size of nucleation sites strongly influences HTC (within an order of magnitude, all other things remain the same), failure to take account of such a crucial factor excludes possibility of adequate description of the process in principle. It also should be stressed that establishment of adequate set of dimensionless numbers without incorporation of the same characteristic size also is impossible in principle.

\section{MTD and MTD-Based Analysis}

Aforementioned main features of developed boiling actually predetermine alternative approach to the problem through assuming existence of certain mechanism controlling developed boiling heat transfer. This mechanism holds given average HTC by multiple triggering of short-run actions of different cooling mechanisms irrespective to variations of the rates of these mechanisms.

At that bubble growth onset is a trigger of main cooling mechanisms. The onset itself is triggered by overcoming by average temperature at the meniscus of critical size the temperature of thermodynamic equilibrium in the nucleusliquid-site system.

Corresponding model of "the theatre of director" (MTD) $[8,20,28-29,74-76]$ incorporates one-parameter model of boiling surface with unlimited number of identical stable nucleation sites. Besides, these sites are characterized by unchangeable level of superheat triggering growth of the first and following bubbles.

The role of such a site may be played by conical recess satisfying the condition:

$\frac{1}{2} \beta<\theta<90^{\circ}$

In the similar site minimum curvature radius of the nucleus (effective radius of a site $\rho_{0}$ ) is equal to the radius of the mouth of the recess [77] (Fig. 24). Besides, cylindrical recess or the recess with narrowed mouth corresponds to this requirement even at zero contact angle.

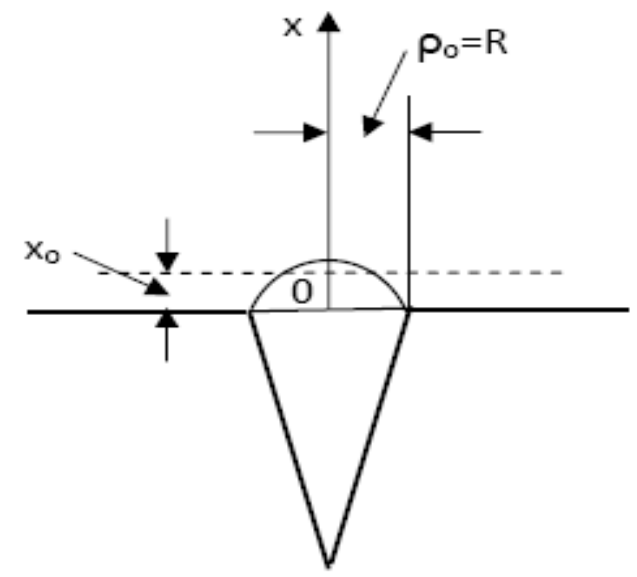

Fig. (24). A scheme of the zone of nucleation site.

To the first approximation, local temperature variation can be approximated by the curve presupposing instantaneous drop in the wall temperature down to the saturation temperature at the onset of bubble growth (instantaneous start-up and shutdown of very intensive heat removal mechanism) and further warming-up of the wall through heat conduction up to the moment of onset of the next bubble growth (Fig. 25).

The superheat $\Delta \mathrm{T}_{\mathrm{eq}}$ necessary for bubble growth onset should be achieved at the meniscus of the nucleus in average. As critical nucleus is in the zone of temperature gradient concomitant heating surface superheat $\Delta \mathrm{T}^{!}$is much above $\Delta \mathrm{T}_{\mathrm{eq}}$. Corresponding unsteady-state process is considered as warming-up of initially isothermal liquid semi-infinite region (with initial temperature equal to $\mathrm{T}_{\mathrm{s}}$ ) through transient heat conduction at suddenly posed boundary condition $\mathrm{q}=$ Const 


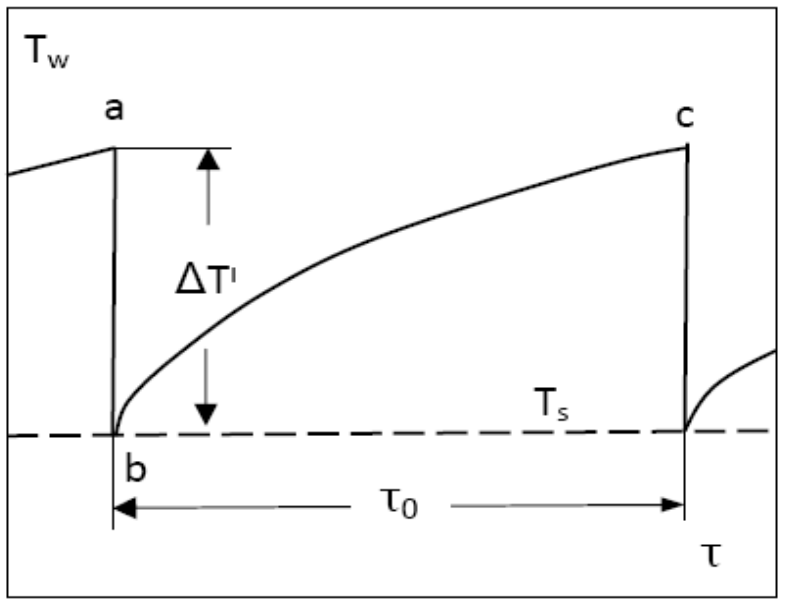

Fig. (25). The first approximation.

(nucleus growth in superheated layer is studied also in [78]). The superheat $\Delta \mathrm{T}_{\mathrm{eq}}$ is determined by the relationship [77]:

$$
\Delta T_{e q}=\frac{2 \sigma T_{s}}{r \rho_{0} \rho_{g}}
$$

General solution of the problem [79] leads to the following equation:

$T(x, \tau)-T_{s}=\frac{2 q}{\lambda} \sqrt{\alpha \tau \operatorname{ierfc} \frac{x}{2 \sqrt{\alpha \tau}}}$

The mean superheat of heating surface accordingly is equal:

$$
\begin{aligned}
\Delta T=\frac{1}{\tau_{0}} \int_{0}^{\tau^{*}}[T(0, \tau) & \left.-T_{s}\right] d \tau= \\
= & \frac{2}{3 \sqrt{\pi}} \frac{q}{k} \sqrt{\alpha \tau^{*}}
\end{aligned}
$$

Written out in non-dimensional form this equation is:

$N u=\frac{3 \sqrt{\pi}}{2} \frac{\rho_{0}}{2 \sqrt{\alpha \tau^{*}}}$,

where:

$N u=\frac{h \rho_{0}}{k}$

The time of climb of heating surface temperature $\tau_{0}$ is the same as the time of attainment by certain section $\mathrm{x}_{0}$ of the meniscus of nuclei of superheat equal to $\Delta \mathrm{T}_{\mathrm{eq}}$. Taking in account $\mathrm{x}_{0} \sim \rho_{0}$, the following relationship is acquired:

$\frac{\rho_{0}}{2 \sqrt{a t}} \frac{1}{\operatorname{ierfc} \frac{\rho_{0}}{2 \sqrt{a t}}}=\frac{K}{2}$,

where:

$$
K=\frac{q \rho_{0}^{2} r \rho_{g}}{\sigma k T_{s}}
$$

The results predicted by equations (6) and (8) are shown in Fig. (26) in the coordinates $N u=f(K)$. Experimental data on HTC during developed boiling of water [80], nitrogen [81] and sodium [82] on commercial surfaces at atmospheric pressure also are plotted (assuming uniform value $\rho_{0} \approx 5 \mu \mathrm{m}$ ).

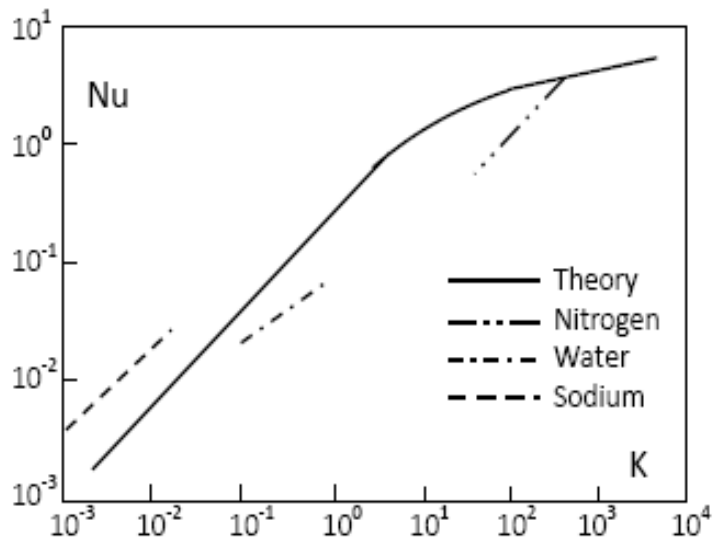

Fig. (26). Comparison of equations (6) and (8) with smoothed experimental curves on boiling at atmospheric pressure: nitrogen [81], water [80] and sodium [82].

Analytical prediction of the order of HTC for greatly differing liquids may be considered as certain support of validity of qualitative basics of MTD. Important outcome of the solution is uncovering of the role of effective radius as characteristic linear size of developed boiling heat transfer. It is important also outlining of the role of the number $\mathrm{K}$. Uncovering of the role of $\rho_{0}$ stresses incompleteness of overwhelming majority of experimental studies of boiling heat transfer. Only exclusive studies have been accompanied by investigation of characteristics of nucleation sites.

Further the theory is refined making emphasis on peculiarities of heat transfer on periphery of action zone of operating nucleation site.

Superheat at the periphery of the action zone makes major contribution to average superheat of the whole zone and to average superheat of heating surface, as a whole. In the framework of MTD and one-parameter model of heating surface the action zone is determined by capability of firstly activated nucleation site to prevent by own cooling effect activation of adjacent potential sites. If the zone of influence of operating site reduces, additional site or sites with the same $\rho_{0}$ turn on operation on the periphery (and vice versa).

In such a manner the "director" holds unchangeable level of superheat just at the periphery of action zone. At that the number of operating sites automatically varies meeting this basic condition. The range of variation of the number may be quite wide, for instance, during significant change of mass acceleration.

Self-control of the number of operating sites depending on cooling effect of separate sites presents a basis for applying to boiling of a theory of self-organized structures [83]. Thereby experimental "discovery of self-organized and cooperative or competitive phenomena among sites or bubbles in boiling systems" [84] presents direct support of MTD. Besides, boiling HTC enhancement through creation of great number of largesized nucleation sites, regarded as the main pragmatic finding 
[83-84], directly was predicted by equations (6) and (8) and by the correlation (16).

Another important peculiarity is decisive role, at the periphery of action zone, of liquid convection always possessing some inertia. Correspondingly, cooling effect may not be shutdown instantly.

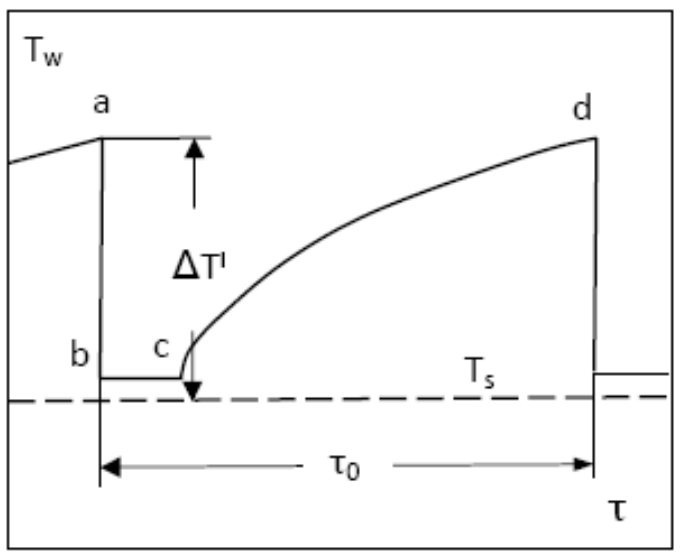

Fig. (27). Approximated temperature behaviour in peripheral zone.

Behavior of heating surface temperature on the periphery can be approximated by the curve presented in Fig. (27). The action of cooling mechanisms is represented by broken curve abc the equivalence of which to the real process can be ensured by suitably selected value of $\tau_{1}$. Surface superheat in this period is considered to be small and its role in the time-average superheating is neglected.

Segment cd characterizes the same warming-up of initially isothermal liquid semi-infinite region. In this case the maximum superheat remains insignificantly less than $\Delta \mathrm{T}^{!}$and can be equated to it. Accordingly, functional relationship for Nusselt number can be widened through introduction of the ratio $\tau_{1} / \tau_{0}$ :

$N u=f\left(K, \tau_{1} / \tau_{0}\right)$

The ratio $\tau_{1} / \tau_{0}$ is determined by viscous dissipation of kinetic energy of liquid motion continuing by inertia. It is, therefore, the function of appropriately specified Reynolds number. Accordingly, equation (10) will acquire the form:

$N u=f(K, \mathrm{Re})$

Certain assumptions also are made on characteristic liquid velocity and characteristic dynamical linear size. Considering a work of expansion as a driver of all dynamical effects, characteristic velocity is evaluated as proportional to square root from the specific work of expansion:

$U \sim C_{1} \sqrt{P\left(v_{g}-v\right)}$,

where $\mathrm{C}_{1}$ is much below of unity.

Characteristic for two-phase hydrodynamics linear size is evaluated for the end of the first stage of bubble growth (to say, to the end of the period of maximum dynamical influence of growing bubble).
As a result following evaluation is derived with the kernel firstly obtained in [58]:

$l \sim \frac{\sigma T_{s} \rho C_{p}}{\left(\rho_{g} r\right)^{2}} f_{1}(K)$

Accordingly, Reynolds number is equal:

$$
\operatorname{Re}=\frac{\sqrt{P\left(v_{g}-v\right)} C_{p} \sigma \rho T_{s}}{\left(r \rho_{g}\right)^{2} v} f_{1}(K)=\operatorname{Re}_{*} f_{1}(K),
$$

where modified Reynolds number comprises only physical parameters of boiling area:

$\operatorname{Re}_{*}=\frac{\sqrt{P\left(v_{g}-v\right)} C_{p} \rho T_{s}}{\left(r \rho_{g}\right)^{2} v}$

Finally, through comparison with experimental data, relationship (11) acquires following form [20]:

$N u=1.22 \cdot 10^{-2} K^{0.7} \operatorname{Re}_{*}^{0.25}$

It also should be mentioned that equation (15) for modified Reynolds number could be presented in more simple form, taking in account that specific work of expansion roughly always is equal to one tenth of specific heat of evaporation. In such a case simplified Reynolds number may be written in following form:

$\operatorname{Re}_{*, s}=\frac{C_{p} \sigma \rho T_{s}}{r^{3 / 2} \rho_{g}^{2} v}$

Accordingly, equation (16) can be transformed to the following form:

$N u=0.88 \cdot 10^{-2} K^{0.7} \operatorname{Re}_{*, s}^{0.25}$

In contrast to equation (16), no dependence of HTC on saturation pressure remains in actually the same equation (16). Thereby the fact is reflected that, in equation (18), specific work of expansion in reality represents specific heat of evaporation. Besides, as according (18) $\mathrm{Nu} \sim\left[\mathrm{P}\left(\mathrm{v}_{\mathrm{g}}-\mathrm{v}\right)\right]^{1 / 8}$, calculation error connected with approximation $\mathrm{P}\left(\mathrm{v}_{\mathrm{g}}-\mathrm{v}\right) \approx 0.1 \mathrm{r}$ is quite insignificant. By the way, in [20] just the form (18) of the correlation is presented.

\section{CORRELATION OF EXPERIMENTAL DATA}

Longstanding disregard of the role of effective radii of nucleation sites has led to essential incompleteness of experimental studies mainly performed without investigation of nucleation sites. In addition, absence of direct dependence of effective radius on standard roughness parameters makes unfeasible attempts to using these parameters for characterization of influence of boiling surface on HTC.

Only very small part of numerous experimental works includes data on sizes and geometry of nucleation sites. It may be assessed as fortunate exclusion the work [47] including measurement of sizes and distribution of operating sites.

At the same time, in certain degree, the situation is mitigated by using in many experiments on boiling heat transfer of commercial heating surfaces (mainly rolled tubes) 
roughly corresponding to one-parameter model of boiling surface.

\section{Correlation of Experimental Data on HTC on Heating Surfaces with Known $\rho_{0}$}

Fortunately, a small number of comprehensive experiments including the values of effective radii covers greatly differing boiling areas and materials of heating surfaces $[47,85-86]$.

Boiling of water [47] is carried out on copper surfaces with average effective radius of operating nucleation sites roughly equal to $5 \mu \mathrm{m}$. Boiling of sodium [85] is studied on stainless steel surface with uniform, rather big $\left(\rho_{0}=50 \mu \mathrm{m}\right)$ stable artificial sites. Boiling of refrigerants [86] is studied on steel surface with big uniform artificial nucleation sites with effective radius equal to $86 \mu \mathrm{m}$.

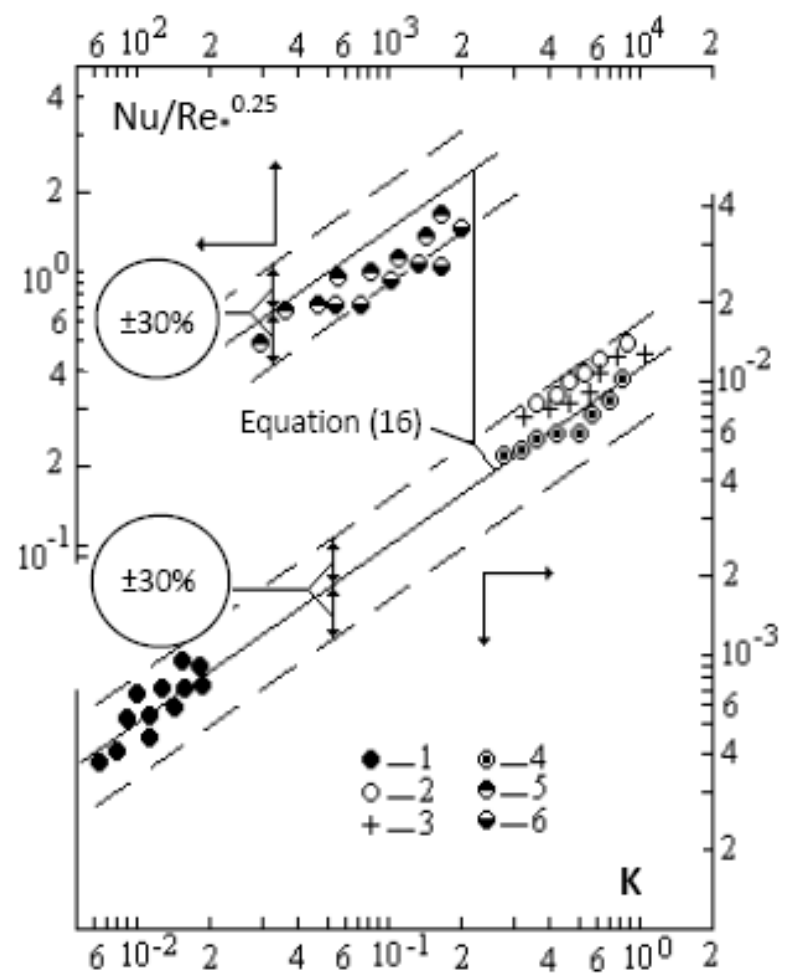

Fig. (28). Comparison of equation.(16) with experimental data on developed boiling on the surfaces with the known values of $\rho_{0}: 1$ - sodium [85], $\rho_{0}=50 \mu \mathrm{m} ; 2-4$ - water [47], $\rho_{0}=5 \mu \mathrm{m} ; 5-\mathrm{R} 12$ [86], $\rho_{0}=86 \mu \mathrm{m} ; 6$ - R 22 [86], $\rho_{0}=86 \mu \mathrm{m}$.

Correlation of experimental data is presented in Fig. (28). The correlation reflects support of MTD by the most comprehensive experimental data. Below we should return to (Fig. 28) in regard to the problem of enhancement of boiling heat transfer.

\section{Correlation of Experimental Data on Developed Boiling on Commercial Surfaces}

Based at some indirect evidences, commercial heating surfaces have been characterized by the average effective radius of nucleation sites equal to $5 \mu \mathrm{m}$ [20]. This assumption is confirmed by experimental data on characteristics of operating nucleation sites [47].

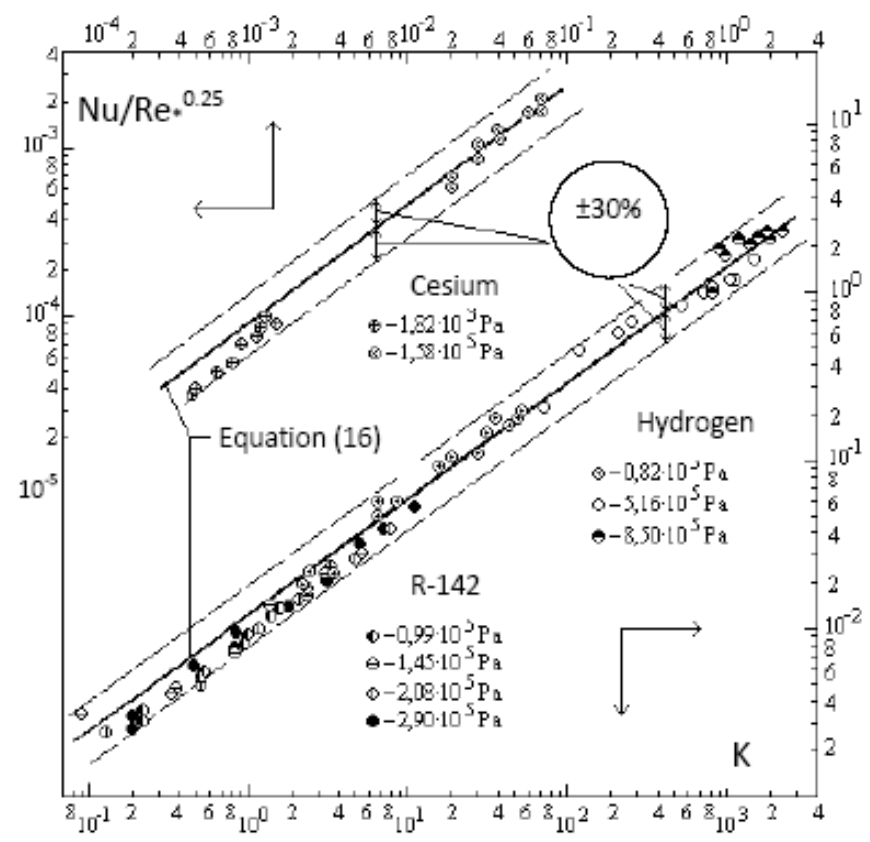

Fig. (29). Correlation of experimental data on developed boiling of cesium [87], R 142 [88] and hydrogen [89] on commercial surfaces $\left(\rho_{0}=5 \mu \mathrm{m}\right)$.

In Fig. (29), as an example, correlation of experimental data on boiling on commercial surfaces of the most "inconvenient" liquids (liquid metals, refrigerants and cryogens) is presented.

Correlation of the data on HTC during boiling of ammonia and five refrigerants on the same heating surface (platinum wire with diameter $0.3 \mathrm{~mm}$ ) under different saturation pressures $[57,90]$ is presented in the Fig. (30). The wire is considered as commercial surface.

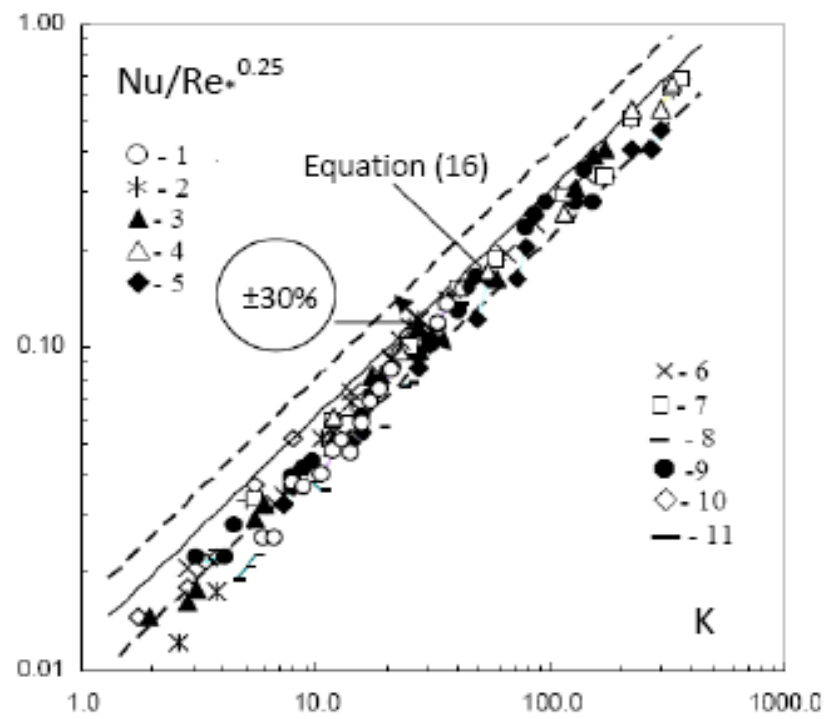

Fig. (30). Correlation of experimental data on developed boiling of 6 different liquids on thin platinum wire: [57]: Ammonia: $1-4-10^{5} \mathrm{~Pa}$; 2 - 7-10 $0^{5}$; [90]: R11: 3 - 4-10 $0^{5} \mathrm{~Pa} ; 4-7-10^{5} \mathrm{~Pa}$; R12: 5 - 4-10 $0^{5} \mathrm{~Pa}$; R22: 6 - 4-10 $0^{5} \mathrm{~Pa} ; 7-7-10^{5} \mathrm{~Pa}$; R113: 8 - 2.5-10 $\mathrm{Pa}$; 9 - 4-10 $\mathrm{Pa}$; R134a: $10-2,5-10^{5} \mathrm{~Pa} ; 11-4-10^{5} \mathrm{~Pa}$. 
Important outcome of the correlation is arrangement of all experimental data along the same unified heat transfer curve. The experimental data (related to the mode of developed boiling) corresponds to equation (16) with accuracy $\pm 30 \%$.

It also should be noted that accepted value of $\rho_{0}$ is only rather well-taken rough approximation. Really this parameter may vary in certain limits even on commercial surfaces causing additional undefined error. For instance, accuracy of the correlation presented in Fig. (30) can be improved up to $\pm 15 \%$ using another value of effective radius $\left(\rho_{0} \approx 3 \mu \mathrm{m}\right)$.

Equation (16) evidently has certain reserve of improvement of accuracy calling for detailed knowledge of nucleation sites. Heretofore we have to limit ourselves by rough evaluation of all commercial surfaces by uniform value of effective radius $\left(\rho_{0}=5 \mu \mathrm{m}\right)$. Thereby we avoid using of the existing uncertainty for fitting of experimental data to the recommended relationship.

Equation (16) correlates wide experimental data on developed boiling heat transfer of all groups of liquids including liquid metals and cryogenic liquids without matching different constants and powers to different surface-liquid combinations.

In particular, the correlation involves experimental data on boiling HTC of water [80], R 12 [88], R 22 [88], R 142 [88], ethyl alcohol [91], benzene [92], biphenyl [92], sodium [93], cesium [87], potassium [82], mercury [94], $\mathrm{CO}$ [95], $\mathrm{NO}$ [95], $\mathrm{BF}_{3}$ [95], ethane [96], ethylene [96], nitrogen [81, 95], neon [89], hydrogen [89] and others. The results of correlations, as a whole, should be considered as a demonstration of fundamental character of MTD.

At the same time, unfortunately, MTD and universal MTD-based correlation more than four decades remain suppressed. Following from these works potential research lines also are left aside consideration. In contrast to it numerous correlations are developed for separate groups of liquids.

\section{Enhancement of Boiling Heat Transfer}

The line of development of high-efficient boiling surfaces presents a fortunate exception in the context of realization of MTD.

The one-parameter model and correlation (16) determine the basic principle of boiling heat transfer enhancement through creation of numerous high-sized stable artificial nucleation sites with minimum worsening of thermal conductance of boiling surface.

The correlation (16) firstly establishes boiling heat transfer enhancement law $\left(h \sim \rho_{0}{ }^{0.4}\right)$ quantitatively predicting achievable results.

During last decades enhanced boiling surfaces have been designed in one-to-one correspondence with this principle. In this context it is reasonable to return to discussion of correlation of experimental data presented in Fig. (28).

Main part of these experiments just is targeted at heat transfer enhancement. Simultaneously they quantitatively verify predicted by equation (16) heat transfer enhancement law. Real enhancement factors, as compared with commercial surfaces, in these experiments achieve around 3 in the case of refrigerants and 2.5 in the case of sodium, in full accordance with equation (16).

At the same time sensible worsening of thermal conductance of boiling surface not always may be avoided. For instance, creation of porous layers always is connected with increase of thermal resistance of heating surface. Besides, negative role of additional thermal resistance becomes more tangible with increase of heat flux. This is why in experiments on enhanced boiling surfaces (for instance, [97, 98]) heat transfer enhancement factor reduces at high fluxes.

In this context the principle of minimum worsening of thermal conductance of heating surface through creation of artificial sites still remains topical through development of enhanced boiling surfaces.

\section{MTD AND MFC}

As it follows from above correlations, developed boiling represents the most conservative basic regime of boiling heat transfer characterized by dependence of HTC on restricted number of influencing factors. Besides, even inter-phase hydrodynamics and geometry (except of the micro-level) have no influence on HTC.

According equation (18), together with physical parameters of boiling area, developed boiling HTC depends only on two "external" factors - heat flux and average effective radius.

As it follows from corresponding analysis, such a conservatism of developed boiling heat transfer can be linked to following three conditions:

- Existence of great (practically unlimited) number of stable nucleation sites with roughly uniform effective radii irrespective are they operating or potential;

- Short duration of each action of any cooling mechanism;

- Prevailing contribution of heat removal by liquid phase convection.

In the context of presented conditions more concrete and narrower definition of the term "developed boiling" can be offered, just restricted by boiling processes corresponding to these conditions.

According to multifactoring concept (MFC) [76] any failure to meet these conditions results essential transformation of heat transfer regularities up to drastic increase of the number of influencing HTC factors.

For instance, depending on concrete conditions, the circle of influencing HTC factors may be widened by parameters of inter-phase hydrodynamics, intensity of body force, contact angle, subcooling, sizes, form, orientation and thermal characteristics of heating surface, micro-geometry and distribution of nucleation sites, and prehistory of the process. Besides, multifactoring may be accompanied by "passing on the baton" from MTD to MTA.

Multifactoring, in such a manner, exhibits some characteristics of critical transition from developed boiling to qualitatively differing boiling regimes. As it follows from 
qualitative consideration, there can be distinguished two main types of multifactoring:

- The first - connected with onset of dependence of effective radius on a degree of penetration of liquid into nucleation site (wetting-dependent multifactoring),

- The second - connected with transition to prolonged duration or uninterrupted regime of action of any intensive cooling mechanism (duration-dependent multifactoring).

\section{Wetting-Dependent Multifactoring}

Wetting-dependent multifactoring occurs in the case $\beta / 2>\vartheta$ when effective radius of nucleation site stops to be a constant equal to the radius of the mouth of the recess.

Immediate transition from developed boiling to this type of multifactoring may be observed only in boiling system with reducing in time contact angle. In the majority of cases developed boiling and wetting-dependent multifactorous boiling of the same liquid may be observed only in separate systems. Dependence of effective radius on a degree of wetting of nucleation site by liquid phase in the case mentioned is presented in Fig. (31).

As it can be shown through simple analysis, in this case effective radius of the site may be determined by following relationship:

$\rho_{0}=\frac{R}{\cos (\beta / 2-\theta)}(1-l / L)$

As it follows from equation (19), effective radius undergoes wide-ranging variation with penetration of liquid into site. Besides, $\rho_{0}$ may be not only much less of $\mathrm{R}$ but even greater than $\mathrm{R}$ (in the case $l<<L$ ).

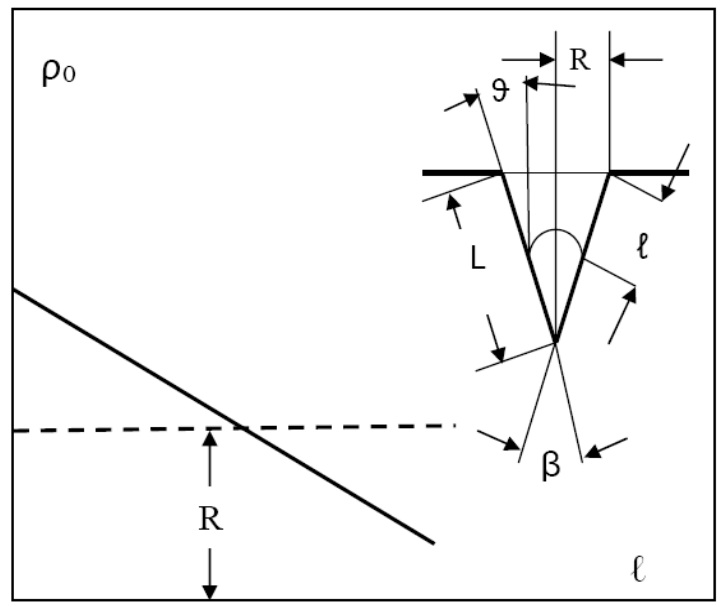

Fig. (31). Dependence of effective radius on a degree of wetting of nucleation site by liquid phase in the case $\beta / 2>\theta$.

As it is shown in [99], conditions of bubble growth onset in operating sites qualitatively differ from potential sites. As transverse size is much smaller far down from the mouth, the first onset of bubble growth in a potential site requires much higher superheat than onset of any subsequent bubble growth. In such a situation the transition of potential site to active condition and vice versa can occur only at markedly different superheats, which in fact is the basis of the hysteresis phenomenon.

Wetting of the site, in general, represents dynamical process depending on velocity and duration of wetting. These parameters, for its part, may be influenced by contact angle, heat flux, prehistory of the process, capability of heating surface to concentrate heat in the zone of wetting meniscus. If wetting length $l$ is small, two highly differing levels of the parameter $\rho_{0}$ take place, the one of order of the radius of the mouth in operating sites and the other, very low one, in potential sites.

Corresponding so-called two-parameter model of boiling surface [74, 99] turns to be fruitful through interpreting specific families of heat transfer curves obtained in experiments on boiling of helium [100] (Fig. 32).

Vertical line 1 corresponds to simultaneous initiation of potential nucleation sites with very small nuclei deepened in the surface $\left(\rho_{0}=\rho_{\min }\right)$ (in this case temperature gradient is negligible in nucleus zone).

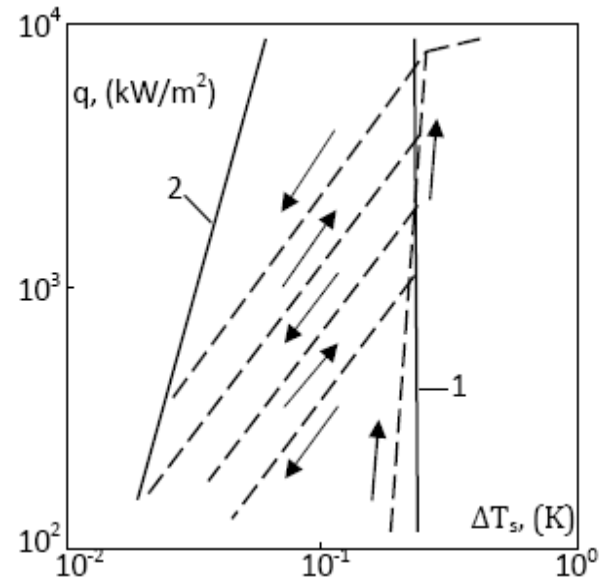

Fig. (32). Smoothed experimental boiling heat transfer curves for helium [100]: 1 - according equation (2), $\rho_{0}=\rho_{\min }=0.01 \mu \mathrm{m} ; 2$ according equation (16), $\rho_{0}=\rho_{\max }=20 \mu \mathrm{m}$.

Inclined line 2 corresponds to developed boiling according to the equation (16) for $\rho_{0}=\rho_{\max }$. Development of the process of boiling in the region of the line 1 is accompanied by steep increase in the number of active nucleation sites. Besides, in the context of aforementioned conclusion, decrease of heat flux at any point of line 1 cannot lead to reduction of the number of operating nucleation sites in the rather wide range of variation of superheat.

In view of this, for any change in heat flux, the process should follow along the lines between the boundaries 1 and 2 without variation in the number of operating sites. By this means a prehistory of the process (degree of climb along line 1) predetermines the boiling curve that may be realized between boundaries 1 and 2 .

It also should be noted that the last comparison has qualitative character, since the actual values of $\rho_{\max }$ and $\rho_{\min }$ are unknown and have been selected on the condition of the best fit to experimental results $\left(\rho_{\min }=0.01 \mu \mathrm{m} ; \rho_{\max }=20 \mu \mathrm{m}\right)$.

Differing situation is to be observed on the heating surface providing stable and uniform effective radii of operating and 
potential sites even in the case $\theta=0$. According MTDMFC such a heating surface should not exhibit boiling heat transfer hysteresis.

This conclusion can be illustrated by experimental data [89] on boiling heat transfer hysteresis manifesting itself vastly on rough surfaces and virtually absent on polished ones.

As it follows from experimental data [47], effective radii of recesses survived through polishing of cooper surface are almost at two orders of magnitude larger than standard roughness parameter of the same surface. Consequently, during the polishing process only the mouths of the recesses are polished and contracted that provides stable equality of effective radii to the radius of the mouth irrespective is the site operating or potential (to say, provides fulfillment of the condition (1) even in the case $\theta=0$ ). According MTD-MFC the last circumstance excludes onset of heat transfer hysteresis.

In the framework of MTD-MFC it also presents significant interest discussion of influence of thermal parameters of heating surface on HTC.

As it was mentioned above, thermal parameters of heating surface have no influence on HTC during developed boiling. In the context of wetting-dependent multifactoring, if process of wetting of a recess is accompanied by reduction of effective radius, deceleration of wetting evidently can result elevation of HTC. High thermal conductivity of heating surface, promoting concentration of heat flow in the zone of wetting meniscus (in the extent additionally dependent on the thickness of the surface), just presents such a decelerating factor.

Therefore, thermal parameters of heating surface, when its recesses correspond to condition (19), should essentially influence HTC. And vice versa, similar influence should not be exhibited by heating surfaces corresponding to condition (2) (to say, during developed boiling).

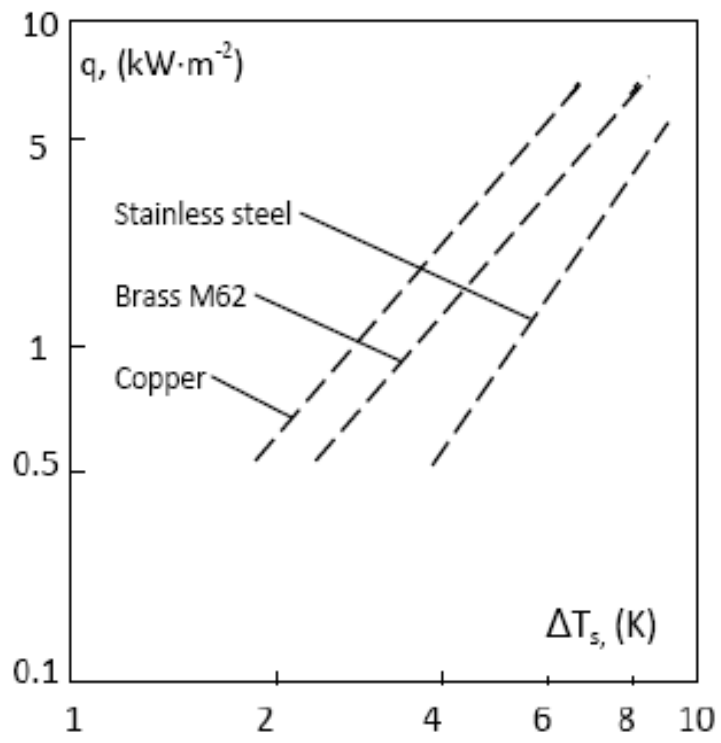

Fig. (33). Smoothed experimental boiling heat transfer curves of nitrogen on rough heating surfaces made from copper, brass and stainless steel [101].
Smoothed experimental curves [101] on boiling of nitrogen on comparatively rough heating surfaces (with the arithmetical mean roughness around $5 \mu \mathrm{m}$ ) made from copper, brass and stainless steel are presented in Fig. (33). According to these data HTC essentially depends on thermal properties of heating surface that can be linked to dependence of effective radius of nucleation site on degree of wetting.

Smoothed experimental curves [102] on boiling of nitrogen on polished surfaces (smooth depth $0.2 \mu \mathrm{m}$ ) made from copper, German Silver and aluminum are presented in Fig. (34).

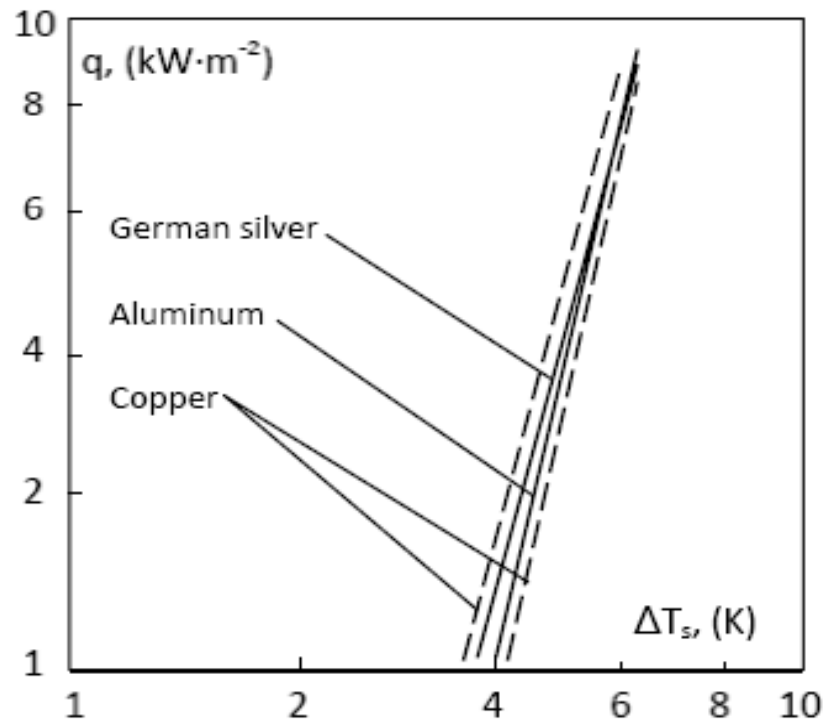

Fig. (34). Smoothed experimental boiling heat transfer curves of nitrogen on polished heating surfaces made from copper, German silver and aluminum [102].

According presented data HTC during boiling on aluminum and German silver surfaces falls within scattering range of the data for copper surface. Besides, thermal conductivity of copper is around 20 times higher than the same parameter of German silver. Practically full absence of influence of thermal properties of heating surface on HTC on polished surfaces, similar to the hysteresis phenomenon, can be interpreted by existence of great number of stable nucleation sites satisfying condition (2).

In such a manner, unified framework MTD-MFC leads to qualitative interpretation of diverse and even seemingly contradictory experimental facts connected with heat transfer hysteresis and influence of thermal parameters of heating surface.

The same framework clearly outlines boundary between developed boiling and wetting-dependent multifactorous boiling.

Despite significant increase of the number of influencing factors, bubble growth onset preserves the role of regulator of average HTC. At the same time, in contrast to developed boiling, heat transfer gains significant new peculiarities quantitative description of which requires modification of MTD, in particular, taking in account dependence of effective radius on several influencing factors. 


\section{Duration-Dependent Multifactoring and Boiling in Microsystems}

Duration-dependent multifactoring quite often may origin consequent to developed boiling, for instance, through transition to prolonged or even uninterrupted action of PEGB or microlayer evaporation with structural transformation of two-phase flow.

Similar transition also may take place with change of intensity of body force or with variation of inclination angle of heating surface in the gravity field.

In contrast to wetting-dependent multifactoring, establishment of conditions of transition to durationdependent multifactoring is much more complex problem. Clarification of quantitative regularities of transition to prolonged action of cooling mechanisms requires consideration of structural development of corresponding two-phase flows that represents independent multifaceted problem.

At the same time, duration-dependent multifactoring results transition to MTA. Thereby, in connection with diversity of cooling mechanisms, the problem of theoretical assessment of HTC becomes extremely complex. It requires comprehensive multifactorous numerical modeling of all details and stages of operation of different cooling mechanisms (similar to attempt made in [103] for the case of subcooled flow boiling).

In the context of duration-dependent multifactoring it presents significant interest boiling in microsystems.

Unfortunately, research of this important problem is affected by delay with development of adequate physical models. That is why attempts to establish efficient framework for correlation of existing data on HTC and CHF still turn out to be unsuccessful [104, 105].

There also are problems with correct choice of strategies of experimental research caused by the same absence of adequate physical models. For instance, it still insufficiently is taken in account essential role of thermal parameters of heating surface in the processes with prevailing role of microlayer evaporation.

Similar to heat transfer hysteresis and influence of thermal parameters, there also exist contradictory experimental data on boiling in the microsystems.

A part of the data shows accordance of heat transfer process to developed boiling and another part demonstrates qualitatively differing trends [104-108].

As it follows from qualitative analysis, seeming chaos in the experimental data, similar to cases considered above, can be resolved in the framework of MTD-MFC.

In general, geometry and transverse sizes of smalldiameter channels support formation and longstanding preservation of vapor plugs shifting through a channel. As it is shown below, shifting vapor plug of very small diameter favors longstanding action of PEGB and microlayer evaporation mechanism. In this connection just transition to prolonged or even uninterrupted action of PEGB and microlayer evaporation claims to be main factors of multifactoring of boiling heat transfer in minichannels and microchannels.
Investigation of boiling multifactoring in small channels evidently presents complex problem covering the stage of multifactoring itself and further stage of multifactorous heat transfer. Besides, in contrast to the steady-state process studied in [18-19], areas with intensive heat transfer are distributed irregularly in space and in time in this case.

In the context of duration-dependent multifactoring it presents significant interest clarification of the role of PEGB in operation of pulsating heat pipe having quite specific peculiarities connected with self-start-up and keeping of pulsating two-phase flow [109-110].

As it follows from preliminary analysis, at very small diameter, very low thickness and possible partial drying of liquid layer between heating surface and the part of vapor plug create quite favorable conditions for strong manifestation of both related phenomena - microlayer evaporation and PEGB.

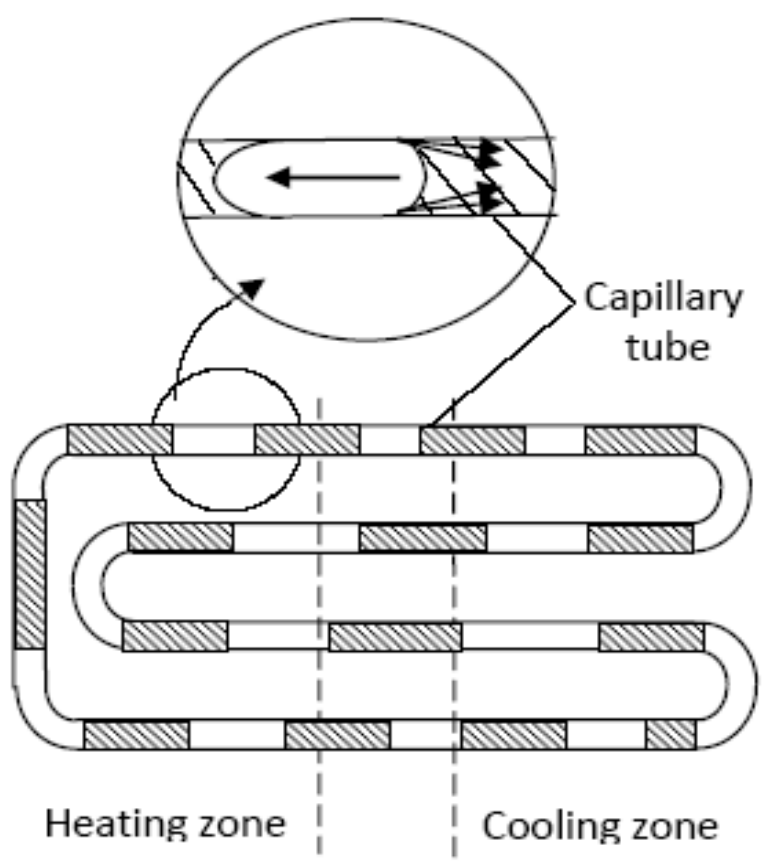

Fig. (35). Pulsating heat pipe.

In contrast to pool boiling, intensive action of the both mechanisms may turn out to be continuous in microchannel (for instance, through shifting of evaporating meniscus along superheated wall). In this context following working hypothesis can be offered regarding operation features of pulsating heat pipe [109-110] (Fig. 35).

During heating in static conditions dynamical effects of jet flows on both sides of vapor plug mainly balance each other and dynamical influence on the system remains insignificant. However, this balance may be lost at any initial displacement of the plug (caused, for instance, by some instant pressure imbalance among different turns of pulsating heat pipe or by occurrence of temperature gradient).

The effect becomes stronger at backside of the plug (where the liquid layer becomes thinner). The plug turns into certain type of jet engine continuing shifting through the channel with self-acceleration. Further this single plug displaces other plugs with the same dynamical effect and several plugs together speed-up circulation of heat carrier in the loop. 
Start-up and acceleration of circulation rather quickly returns the most cooled part of heat carrier from cooling zone. Condensation replaces evaporation on inlet plugs with change of the sign of pumping effect. In addition, evaporation weakens on other plugs.

Arising of opposite pumping effect, together with elimination of initial traction, quickly decelerates the circulation with consequent rise in temperature of heat carrier in heating zone. As a result, initial pumping effect and heat carrier circulation is reversed. Further this sequence repeats periodically.

Offered working hypothesis, with the exception of negative loop feedback aspects, is quite topical also in regard boiling in the microsystems, as a whole. In particular, prolonged duration of intensive action of PEGB and microlayer evaporation may create basis not only for boiling heat transfer multifactoring but for some specific dynamical effects as well.

For instance, it may be discussed the role of PEGB in generation of strong reverse vapor follows, related cyclical oscillations and flow instabilities observed in minichannels and microchannels $[105,111]$. It may be shown also that pumping effect of a vapor slug undergoes sharp intensification near to critical regime of channel flow (in connection with partial drying of liquid layer). Generated in such a way strong liquid jet flow may push off the next slug causing reverse of its own pumping effect. As a result, just similar slug may be responsible for aforementioned reverse flows.

\section{THE WAYS OF FURTHER RESEARCH}

Following from MTD fundamental boiling heat transfer problem (establishment of interrelations between diversity of boiling heat transfer curves and sizes, geometrics and distribution of nucleation sites) still remains to be studied systematically. Only very small part of numerous experiments includes investigation of nucleation sites. Still are underway unworkable attempts to substitute standard roughness parameters for the effective radii of nucleation sites.

Despite impressive experimental evidences of crucial role of PEGB in boiling heat transfer and hydrodynamics, the effect still remains outside of scope of interests of overwhelming majority of researchers.

Wide theoretical and experimental investigations of PEGB are necessary by the goal of clarification of all spectra of important features of the effect beginning from generation of jet flow and ending by its dynamical and thermal consequences. Investigations should cover nongravity mechanism of vapor phase removal most likely playing leading role through boiling crisis at low saturation pressures and in microgravity, during forced convection boiling in minichannels and microchannels. At the same time it deserves certain interest investigation of micro-membrane pumping effect as additional convection cooling mechanism.

It still remains as the central problem physical modeling of developed boiling on one-parameter heating surfaces and on surfaces with more complex distribution of characteristic sizes and densities of nucleation sites in wide range of variation of effective radius and saturation pressure.

Two possible lines of such a modeling deserve attention: artificial creation of boiling surfaces with designed parameters of nucleation sites and improvement of methods of investigation of natural nucleation sites of heating surfaces.

Full-scale investigation of these processes in the framework MTD-MFC may create basis for analysis of wide spectra of boiling heat transfer problems including quite interesting problem of the slope of developed boiling heat transfer curve.

It is important and capacious problem theoretical and experimental investigation of the phenomenon of boiling heat transfer multifactoring. Investigation of wetting-dependent and duration-dependent multifactoring should cover such an important aspects of boiling phenomenon as heat transfer hysteresis, heat transfer at variable average effective radii of nucleation sites, heat transfer processes with prolonged action of PEGB and microlayer evaporation including boiling in minichannels and microchannels, some specific regimes of boiling in subcooled liquids, in microgravity, on down facing boiling surfaces and others. Besides, investigation of transient behavior in the framework MTD-MFC makes new potential for thorough insight into boiling phenomenon.

Unified framework MTD-MFC opens the way to comprehensive research of important problem of boiling in the microsystems. It is necessary to upgrade existing approaches and physical models taking in account dynamical and thermal consequences of prolongation of intensive action of PEGB and transition to almost uninterrupted action of microlayer evaporation mechanism.

Determined by correlation (16) basic principle of intensification of boiling heat transfer (creation of numerous high-sized stable nucleation sites with minimum worsening of thermal conductance of boiling surface) still remains as the most efficient line of development of enhanced boiling surfaces. Correspondingly, improvement of technologies of manufacturing of boiling surfaces also should be targeted at full realization of this principle.

NOMENCLATURE

\begin{tabular}{|c|c|c|}
\hline $\mathrm{A}$ & {$\left[\mathrm{m}^{2}\right]$} & Heating surface area \\
\hline $\mathrm{C}_{\mathrm{p}}$ & {$\left[\mathrm{J} \cdot \mathrm{kg}^{-1} \cdot \mathrm{K}^{-1}\right]$} & Heat capacity \\
\hline $\mathrm{L}$ & {$[\mathrm{m}]$} & length of conical site side \\
\hline $\mathrm{N}$ & {$\left[\mathrm{m}^{-2}\right]$} & Density of operating sites \\
\hline $\mathrm{P}$ & {$[\mathrm{Pa}]$} & Pressure \\
\hline
\end{tabular}




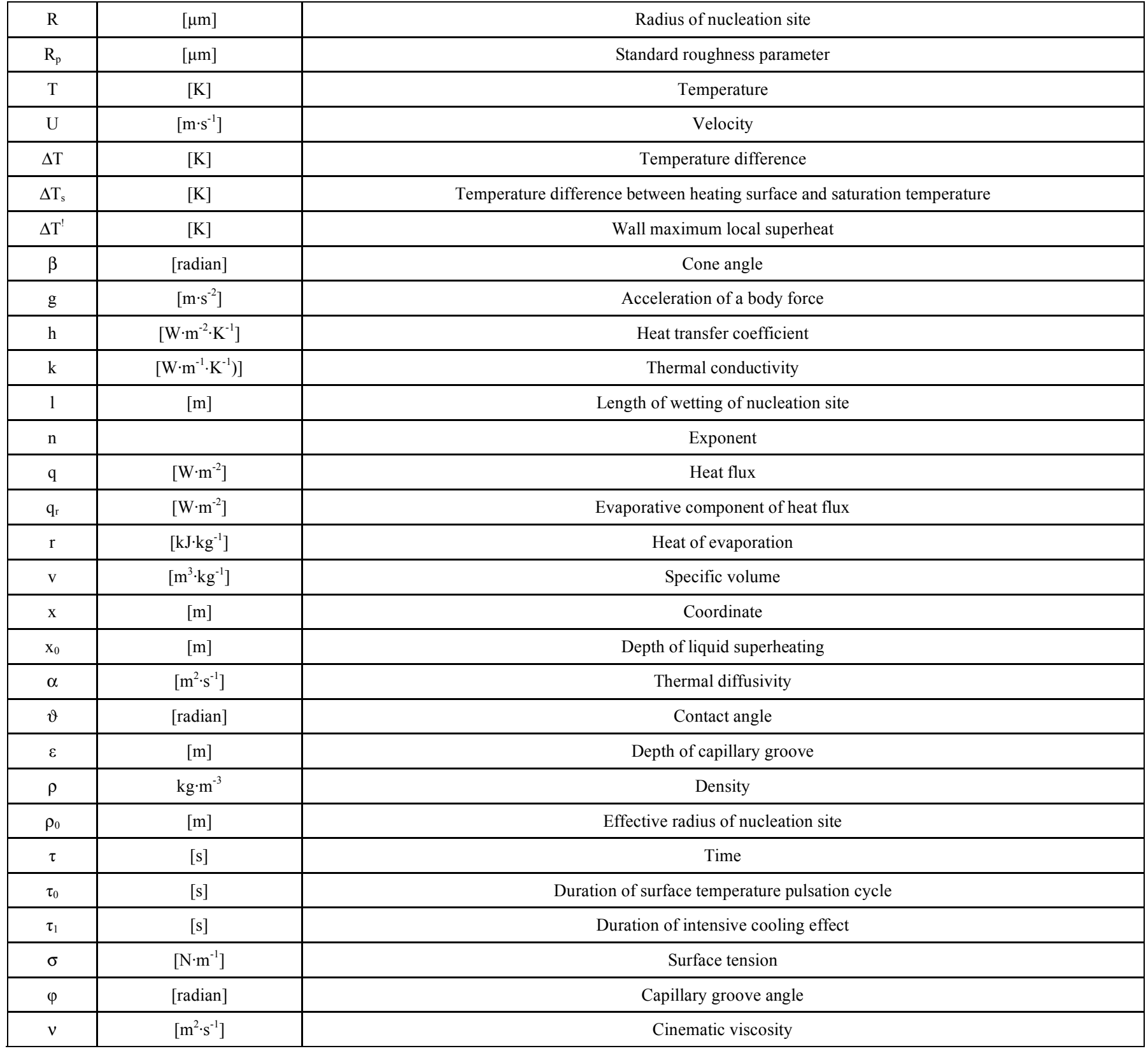

\section{SUBSCRIPTS}

\begin{tabular}{|c|c|}
\hline $\mathrm{cr}$ & Critical value \\
\hline $\mathrm{g}$ & Refers to vapor (fluid - without subscript) \\
\hline $\mathrm{gd}$ & According hydrodynamic theory of crisis \\
\hline $\mathrm{eq}$ & Refers to equilibrium condition \\
\hline 0 & Under normal gravity \\
\hline $\mathrm{s}$ & At saturation condition \\
\hline $\mathrm{w}$ & On the wall \\
\hline
\end{tabular}

\section{REFERENCES}

[1] I.L. Pioro, W.M. Rohsenow, and S.S. Doerffer, "Nucleate poolboiling heat transfer, 1: review of parametric effects of boiling surface", Int. J. Heat Mass Transf., vol. 47, pp. 5033-5044, December 2004
[2] I.L. Pioro, W.M. Rohsenow, and S.S. Doerffer, "Nucleate poolboiling heat transfer, 2: assessment of prediction methods", Int. J. Heat Mass Transf., vol. 47, pp. 5045-5057, December 2004.

[3] K.V. Dhir, "Mechanistic prediction of nucleate boiling heat transfer achievable or hopeless task?" J. Heat Transf., vol. 128, pp. 1-12, January 2006. 
[4] I.G. Shekriladze, and J.G. Rusishvili, "Comments on papers L. Pioro, W. Rosenow, and S.S. Doerfer, "Nucleate pool-boiling heat transfer, 1: review of parametric effects of boiling surface; 2: assessment of prediction methods", Int. J. Heat Mass Transf., vol. 49, pp. 1205-1207, March 2006.

[5] F.D. Moore and R.B. Mesler, "The measurement of rapid surface temperature fluctuations during nucleate boiling of water", AICHE J., vol. 7, pp. 620-624, April 1961.

[6] M. Jacob, Heat Transf.. Vol. 1, NY: John Wiley, 1949.

[7] H.K. Forster and R. Greif, "Heat transfer in boiling liquid, mechanism and correlations", Tr. ASME, J. Heat Transf., vol. 81, pp. 43-53, January 1959.

[8] I.G. Shekriladze, "On the mechanism of nucleate boiling", Bull. Acad. Sci. Georg. SSR, vol. 41, pp. 392-396, February 1966 (English version: I.G. Shekriladze, "Mechanism of Steam bubble formation", NASA TM X - 59 398, January 1967. [Online] Available:

http://ntrs.nasa.gov/search.jsp?N=0\&Ntk=AuthorList $\& N t x=\bmod$ $\mathrm{e} \% 20$ matchall\&Ntt=shekriladze. [Accessed Nov 11, 2006]).

[9] T.T. Robin and N.W. Snyder, "Bubble dynamics in subcooled nucleate boiling based on the mass transfer mechanism", Int. J. Heat Mass Transf., vol. 13, pp. 305-318, February 1970.

[10] Ye.I. Nesis and I.S. Sologub, "Temperature fluctuations in subcooled boiling at a single site", in: Kipenie i kondensatsia, I. Smirnov, Ed. Riga: RPI Press, 1984, pp. 5-13.

[11] I.G. Shekriladze, "Heat transfer in two-phase areas with intensive evaporation and condensation", Dr. Tech. Sc. dissertation, Moscow Bauman Higher Technical School, Moscow, USSR, 1982.

[12] V.I. Tolubinski, A.A. Kriveshko, and Yu. N. Ostrovski, “About temperature fluctuations of heating surface under active nucleation site", Teplofizika i teplotekhnika, Issue 19, V. Tolubinski, Ed. Kiev, Naukova Dumka Press, 1971, pp. 22-26.

[13] S.J. Van Stralen, W. Zijl, and D.A. De Vries, "The behavior of vapor bubbles during growth at subatmospheric pressures", Chem. Eng. Sci., vol. 32, pp. 1189-1196, October 1977.

[14] I.G. Shekriladze, Sh.A. Mestvirishvili, J.G. Rusishvili, G.I. Zhoszholiani, and V.G. Ratiani, "Study of heating surface temperature fluctuations in the process of liquid boiling", Bull. Acad. Sci. Georg. SSR, vol. 89, pp. 69-72, January 1978.

[15] R.L. Judd and K.S. Hwang, "A comprehensive model for nucleate pool boiling heat transfer including microlayer evaporation", J. Heat Transf., vol. 98, pp. 623-629, May 1976.

[16] J.R. Thome, "Latent and sensible heat-transfer rates in the boiling of binary mixtures", J. Heat Transf., vol. 104, pp. 474478, April 1982.

[17] M.V.H. Del Valle and D.B.R. Kenning, "Subcooled flow boiling at high heat flux", Int. J. Heat Mass Transf., vol. 28, pp. 19071920, October 1983.

[18] G.V. Ratiani, Sh. A. Mestvirishvili, and I.G. Shekriladze, "Analysis of two cases of evaporation from thin laminar films", Bull. Acad. Sci. Georg. SSR, vol. 55, pp. 325-328, March 1969.

[19] I.G. Shekriladze and J.G. Rusishvili, "Evaporation and condensation on grooved capillary surfaces", Proceedings of 6th International Heat Pipe Conference, 1987, pp. 234-239.

[20] I.G. Shekriladze and G.V. Ratiani, "On the basic regularities of developed nucleate boiling heat transfer", Bull. Acad. Sci. Georg. $S S R$, vol. 42, pp. 145-150, January 1966.

[21] L. Bard and E.F. Leonard, "Heat transfer in simulated boiling", Int. J. Heat Mass Transf., vol. 10, pp. 1727-1734, December 1967.

[22] S.S. Kutateladze and I.G. Malenkov, "The hydrogasodynamic aspects of liquid boiling heat transfer", Teplofizika Visokikh Temp. vol. 14, pp. 793-803, July 1976.

[23] I.G. Shekriladze, "On the role of the "pumping effect" of a vapour bubble growing at the wall during nucleate boiling", in Problems of Convection Heat Transf. and Steam Purity, V.I. Gomelauri, Ed. Tbilisi, Metsniereba Press, 1970, pp. 90-97.

[24] H. Schlichting, Boundary-Layer Theory. NY: McGraw-Hill, 1979.

[25] I.G. Shekriladze, Sh. A. Mestvirishvili, J.G. Rusishvili, G.I. Zhoszholiani, and V.G. Ratiani, "Studies in the mechanism of boiling and enhancement of evaporative cooling coefficients", Heat Transf.-Soviet Res., vol. 12. pp. 91-95, February 1980.

[26] V.I. Subbotin, S.P. Kaznovski, and S.K. Korotaev, "Investigation of the dynamics of vapour bubbles in boiling of water on thin wires under natural convection”, Atomnaia Energia, vol. 28, pp. 9-13, January 1970.

[27] O.N. Afgan, Boiling Liquids Superheat. Oxford: Pergamon Press, 1976.

[28] I.G. Shekriladze, "Mechanisms of heat removal in the process of developed boiling", Heat Transf.-Soviet Res., vol. 22, pp. 445-463, April 1990.

[29] I.G. Shekriladze, "Frozen pathways to breakthrough in boiling heat transfer theory", Proceedings of. 11th International Heat Transfer Conerence, Vol. 2, 1998, pp. 474-478.

[30] I.G. Shekriladze, Comments on the paper, "Jet flow phenomena during nucleate boiling”, Int. J. Heat Mass Transf., vol. 46, pp. 27112712, July 2003.

[31] H. Wang, X.F. Peng, B.X. Wang and D.J. Lee, "Jet flow phenomena during nucleate boiling”, Int. J. Heat Mass Transf., vol. 45, pp. 13591363, March 2002.

[32] B.S. Yilbas and M. Sami, "Liquid ejection and possible nucleate boiling mechanisms in relation to laser drilling process", J. Phys. D. Appl. Phys., vol. 30, pp. 1996-2005, November 1997.

[33] H. Wang, X. Peng, D.M. Christopher, W.K. Lin and C. Pan, "Investigation of bubble-jet flow during subcooled boiling on wires", Int. J. Heat Fluid Flow, vol. 26, pp. 485-494, March 2005.

[34] H. Wang, X. Peng, D.M, Christopher and S.V. Garimella, "Jet flows around microbubbles in subcooled boiling", J. Heat Transf., vol. 127, pp. 802, August 2005.

[35] J.L. McGraw, F.L. Bamford and T.R. Rehm, "Marangoni flow: additional mechanism in boiling heat transfer", Science, vol. 153, pp. 1106-1107, 2 September 1966.

[36] J. Betz and J. Straub, "Numerical and experimental study of the heat transfer and fluid flow by thermocapillary convection around gas bubble", Heat Mass Transf., vol. 37, pp. 215-227, February 2001.

[37] D.M. Christopher, H. Wang and X. Peng, "Dynamics of bubble motion and bubble top jet flows from moving vapor bubbles on microwires", J. Heat Transf., vol. 127, pp. 1260-1268, November 2005.

[38] I.G. Shekriladze, Discussion: "Dynamics of bubble motion and bubble top jet flows from moving vapour bubbles on microwires", $J$. Heat Transf., vol. 127, pp. 1260-1261, December 2006.

[39] J.W. Rose, "Interphase matter transfer, the condensation coefficient and dropwise condensation", Proceedings of 11th International Heat Transfer Conerence, Vol. 1, 1998, pp. 89-94.

[40] S.S. Kutateladze, Heat Transf. in Condensation and Boiling. Moscow: Mashgiz Press, 1952.

[41] D.A. Clark, "Cryogenic heat transfer", in Uspekhi Teploperedachi, W.M. Rohsenow and J.P. Hartnet, Eds. Moscow: Mir Press, 1971, pp. 361-367.

[42] J. Straub, M. Zeil and B. Vogel, "Pool boiling in a reduced gravity field", Proceedings of 9th International Heat Transfer Conerence, Vol. 1, 1990, pp. 91-112.

[43] T. Oka, Y. Abe, Y.H. Mori and A. Nagashima, "Pool boiling of npemtane, CFC, and water under reduced gravity: parabolic flight experiments with a transparent heater", J. Heat Transf., vol. 117, pp. 408-417, February 1995.

[44] V.I. Subbotin, D.N. Sorokin, D.M. Ovechkin, and A.P. Kudriavtsev, "Heat Transf. during Pool Boiling of Metals". Moscow: Nauka Press, 1969.

[45] I.G. Shekriladze, Yu. Sh. Verulava, L. Ye. Vasadze, and M.S. Paniashvili, "An experimental investigation of heat transfer and critical heat fluxes during Boiling of organic working bodies and water under reduced pressures", J. Eng. Phys., vol. 40, pp. 689-693, June 1981.

[46] G.V. Ratiani and I.G. Shekriladze, "Study of the process of fully developed boiling of liquids", Heat Transf.-Soviet Res., vol. 4, pp. 126-141, January 1972.

[47] M. Shoukri and R.L. Judd, "Nucleation site activation in saturated boiling", J. Heat Transf., vol. 97, pp. 96-102, January 1975.

[48] R. Ziegel, Heat Transf. Under Reduced Gravitation. Moscow: Mir Press, 1970.

[49] A.A. Voloshko, "Effects of microgravity and dynamic acceleration on physical characteristics and heat transfer intensity under liquid boiling", presented at International Symposium Physics and Heat Transfer Boiling Condensation, Moscow, Russia, 1996.

[50] A.I. Butuzov, S.N. Faisilberg, M.K. Bezrodny, N.I. Stogny, P.P. Kudelia, and V.I. Usenko, "Experimental data on pool Boiling of refrigerant-12 and water under inertial reloading", Teplofizika visokikh Temp., vol. 7, pp. 490-494, March 1969. 
[51] J. Kim and J.F. Benton, "Highly subcooled pool boiling heat transfer at various gravity levels", Int. J. Heat Fluid Flow, vol. 23, pp. 497-508, February 2002.

[52] J. Kim and J.F. Benton, "Pool boiling heat transfer on small heaters: effect of gravity and subcooling", Int. J. Heat Mass Transf., vol. 45, pp. 3919-3932, October 2002.

[53] L.T. Hwang, W.F. Lu, and J.C. Mollendorf, "Forced convective boiling in horizontal tube bundles", Int. J. Heat Mass Transf., vol. 29, pp. 785-795, May 1986.

[54] Yu. A. Zaigarnik, "Forced convection boiling", in International Encyclopedia of Heat and Mass Transfer, Boca Raton: CRC Press, 2000, pp. 464-467.

[55] K. Nishikava, Y. Fujita, S. Uchida, and H. Ohta, "Effect of surface configuration on nucleate boiling heat transfer", Int. J. Heat Mass Transf., vol. 27, pp. 1559-1571, September 1984.

[56] J.L. Parker, and M.S. El-Genk, "Effect of surface orientation on nucleate boiling of FC-72 on porous graphite", J. Heat Transf., vol. 128, pp. 1159-1175, November 2006.

[57] T. Inoue, M. Monde, and Y. Teruya, "Pool boiling heat transfer in binary mixtures of ammonia/water", Int. J. Heat Mass Transf., vol. 45, pp. 4409-4415, November 2002.

[58] G.N. Kruzhilin, "Heat transfer from heating surface to boiling single-component liquid in conditions of natural convection", Izvestia AN SSSR, OTN, vol. 7, pp. 967-980, July 1948.

[59] W.M. Rohsenow, "A Method of correlating heat transfer data for surface boiling of liquids", Trans. ASME, vol. 74, pp. 969-976, August 1952.

[60] V.I. Tolubinski, "The problem of boiling heat transfer theory", Izvestia VUZ, Energetika, vol. 1, pp. 15-22, January 1959.

[61] H.M. Kurihara, and J.E, Meyers, "The effects of superheat and surface roughness on boiling coefficients", AICHE J., vol. 6, pp. 83-91, January 1960.

[62] J.H. Lienhard, "A Semi-rational nucleate boiling heat flux correlation”, Int. J. Heat Mass Transf., vol. 6, pp. 215-219, March 1963.

[63] N. Zuber, "Nucleate boiling: region of isolated bubbles and the similarity with natural convection", Int. J. Heat Mass Transf., vol. 6, pp. 53-58, January 1963.

[64] S.S. Kutateladze, A.I. Leontiev, and A.G. Kirdiashkin, "Nucleate boiling heat transfer theory", Ingenerno-Physichesi J. vol. 8, pp. 7-12, August 1965.

[65] B.B. Micic, and W.M. Rohsenow, "A New correlation of poolboiling data including the effect of heating surface characteristics", J. Heat Transf., vol. 91, pp. 245-250, February 1969.

[66] S.A. Labuntsov, "Problem of heat transfer during nucleate boiling of liquids", Teploenegretika, vol. 9, September 1972.

[67] K. Stephan, and M. Abdelsalam, "Heat transfer correlations for natural convection boiling", Int. J. Heat Mass Transf., vol. 23, pp. 73-77, January 1980.

[68] S.A. Kandlikar, "General correlation for saturated two-phase flow boiling heat transfer inside horizontal and vertical tubes", $J$. Heat Transf., vol. 112, pp. 219-228, January 1990.

[69] K.O. Pasamehmetoglu, P.R. Chappidi, C. Unal, and R.A. Nelson, "Saturated pool nucleate boiling mechanisms at high heat fluxes", Int. J. Heat Mass Transf., vol. 36, pp. 3859-3868, August 1993.

[70] S.I. Haider and R.L. Webb, "A transient micro-convection model of nucleate pool boiling”, Int. J. Heat Mass Transf., vol. 40, pp. 3675-3688, August 1997.

[71] V.K. Dhir, "Numerical simulation of pool-boiling heat transfer", AICHE J., vol. 47, pp. 813-834, April 2001.

[72] Y. He, M. Shoji and Sh. Maruyama, "Numerical study of high heat flux pool boiling heat transfer", Int. J. Heat Mass Transf., vol. 44, pp. 2357-2373, June 2001.

[73] T. Fuchs, J. Kern, and P. Stephan, "A transient nucleate boiling model including microscale effects and wall heat transfer", $J$. Heat Transf., vol. 128, pp. 1257-1265, December 2006.

[74] I.G. Shekriladze, "Developed boiling heat transfer", Int. J. Heat Mass Transf., vol. 24, pp. 795-01, May 1981.

[75] I.G. Shekriladze, "Developed boiling heat transfer of cryogenic liquids and refrigerants", in Heat and Mass Transf. in Refrigeration and Cryogenics, N. Afgan, Ed. Washington: Hemisphere, 1987, pp. 580-591.

[76] I.G. Shekriladze, "Developed boiling heat transfer - forty years of the model of "the theatre of director", presented at $13^{\text {th }}$ International Heat Transfer Conference, Sydney, Australia, 2006.
[77] P. Griffith and S.D. Wallis, "The role of surface conditions in nucleate boiling", Chem. Eng. Prog. (symp. ser.), vol. 56 (30), pp. 4960, December 1960.

[78] M. Madejski, "Activation of nucleation cavities on a heating surface with temperature gradient in a superheated liquid", Int. J. Heat Mass Transf., vol. 9, pp. 295-300, April 1966.

[79] A.V. Luikov, Heat Conduction Theory. Moscow: Visshaia Shkola Press, 1967.

[80] V.M. Borishanski, A.P. Kozirev, and A.S. Svetlova, "Investigation of heat transfer during nucleate boiling of liquids", in Convection Heat Transf. and Hydrodynamics in Two-Phase and Single-Phase Flows, V.M. Borishanski, Ed. Moscow: Gosenergoizdat Press, 1964, pp. 71104.

[81] A.C. Dudkevich, F.D. Akhmedov, "Experimental study of influence of thermophysical properties of heating surface on boiling of nitrogen at elevated pressures", Trudi, MEI; Issue 198, pp. 41-47, September 1974.

[82] V.M. Borishanski, S.S. Kutateladze, and I.I. Novikov, Liquid Metal Heat Carriers. Moscow: Atomizdat Press, 1967.

[83] L.H. Chai and M. Shoji, "Self-organization and self-similarity in boiling systems", J. Heat Transf., vol. 124, pp. 507-515, March 2002.

[84] L.H. Chai and M. Shoji, "Closure to discussion "Self-organization and self-similarity in boiling systems", J. Heat Transf., vol. 126, pp. 663-664, April 2004.

[85] P.L. Marto and W.M. Rohsenow, "Effects of surface conditions on nucleate pool boiling of sodium", J. Heat Transf., vol. 88, pp. 149157, February 1966.

[86] L.V. Chumak, L.V. Malaia, and I.V. Vinichenko, "Enhancement of heat transfer of cryogens on the pipe surface", Kholodilnaia Tekhnika, vol. 2, pp. 31-34, Februay 1979.

[87] V.I. Subbotin, D.M. Ovechkin, and D.N. Sorokin, "Heat transfer during pool boiling of cesium", Teploenergetika, vol. 6, pp. 63-66, June 1968.

[88] G.N. Danilova, "Influence of saturation pressure and temperature on heat transfer during boiling of refrigerants", Trudi CKTI, vol. 57, pp. 69-80, January 1965.

[89] V.A. Grigoriev, Yu. M. Pavlov, and E.V. Ametistov, Boiling of Cryogenic Liquids. Moscow: Energia Press, 1973.

[90] T, Inoue, N. Kawae and M. Monde, "Characteristics of heat transfer coefficient during nucleate pool boiling of binary mixtures", Heat Mass Transf., vol. 33, pp. 337-344, April 1998.

[91] V.M. Borishanski, G.I. Bobrovich, and F.P. Minchenko, "Heat transfer during boiling of water and ethyl alcohol at external surface of tubes", in Problems of Heat Transf. and Hydrodynamics in TwoPhase Area, V. M. Borishanski, Ed. Moscow: Gosenergoizdat Press, 1961, pp. 75-93.

[92] Hene and Guber, "Boiling of benzene, biphenyl and benzenebiphenyl mixtures", J.Heat Transf., vol. 85, pp. 31-38, March 1963 (Russian Translated Edition).

[93] B.S. Petukhov, S.A. Kovalev, and V.M. Zhukov, "Study of sodium boiling heat transfer", Proceedings of 3rd International Heat Transfer Conerence, Vol. 5, 1966, pp. 80-91.

[94] A.I. Pridantsev, L.S. Kokorev, V.I. Deev, and V.I. Petrovichev, "Experimental study of regimes and heat transfer during boiling of mercury under subatmospheric pressures", in Problems of Thermophysics of Nuclear Reactors, Issue 3, V.I. Subbotin, Ed. Moscow: Atomizdat Press, 1971, pp. 3-12.

[95] I.G. Shekriladze and J.G. Rusishvili, "Experimental study of heat transfer during boiling and condensation of cryogens", IngenernoPhysicheski J., vol. 33, pp. 486-490, March 1977.

[96] V.A. Kravchenko and L.F. Tolubinskaia, "Heat transfer during boiling of ethan and ethylene", Teplophizika i Teplotekhnika, V. Tolubinski, Ed. Issue 31, pp. 61-64, January 1976.

[97] Y. Xiulin, X. Hongji, Z. Yuweng, and Q. Hongzhang, "Pool boiling heat transfer to liquid nitrogen from porous metallic coatings of tube bundles and experimental research of hysteresis phenomenon", Cryogenics, vol. 29, pp. 460-462, April 1989.

[98] R.L Webb and Ch. Pais, "Nucleate pool boiling data for five refrigerants on plain, integral-fin and enhanced tube geometries", Int. J. Heat Mass Transf., vol. 35, pp. 1893-1904, February 1992.

[99] I.G. Shekriladze, "On the mechanism of heat transfer hysteresis in the process of boiling", Bull. Acad. Sci. Georg. SSR, vol. 101, pp. 325328, February 1981.

[100] V.K. Andreyev, V.I. Deyev, V.I. Petrovichev, and G.S. Shelukhina, "Heat transfer regimes in bubble pool boiling of helium", Teplofizika visokikh Temp., vol. 16, pp. 882-884, April 1978. 
[101] V.A. Grigoriev, Yu. M. Pavlov, E.V. Ametistov, A.V. Klimenko, and V.V. Klimenko, "Concerning the influence of thermal properties of heating surfaccce material on heat transfer intensity of nucleate pool boiling of liquids including cryogenic ones", Cryogenics, vol. 17, pp. 94-96, February 1977.

[102] H. Ackerman, B. Bewilogua, and H. Vinzelberg, "Bubble boiling from heated surface of different material in liquid nitrogen", Cryogenics, vol. 15, pp. 877-878, November 1975.

[103] N. Basu, G.R. Warrier and V.K. Dhir, "Wall heat flux partioning during subcooled flow boiling", J. Heat Transf., vol. 127, pp. 131-140, January 2005.

[104] S. Kandlikar, Heat Transfer and Fluid Flow in Minichannels and Microchannels, London: Elsveier, 2006.

[105] J.R. Thome, "Fundamentals of boiling and two-phase flow in microchannels", presented at $13^{\text {th }}$ International Heat Transfer Conference, Sydney, Australia, 2006.
[106] S.S. Mehendale, and A.M. Jacobi, "Evaporative heat transfer in mesoscale heat exchangers", ASHRAE Trans., vol. 106, pp. 446-452, February 2000.

[107] A.E. Bergles, V.J.H. Leinhard, G.E. Kendall, and P. Griffith, "Boiling and evaporation in small diameter channels", Heat Transf. Eng., vol. 24, pp. 18-40, January 2003.

[108] J.R. Thome, M. Groll, and R. Mertz, "Microscale Heat transfer: boiling and evaporation", in Heat Exchanger Design Update, G. Hewitt, Ed. NY: Begell House, 2003, pp. 1-27.

[109] H. Yang, S. Khandekar, and M. Groll, "Operational limit of closed loop pulsating heat pipes", App. Ther. Eng., vol. 28, pp. 49-59, January 2008.

[110] W. Qu and H.B. Ma, "Theoretical analysis of start-up of pulsating heat pipe", Int. J. Heat Mass Transf., vol. 50, pp. 2309-2316, June 2007.

[111] P. Cheng, H.-Y. Wu, and F.-J. Hong, "Phase-change heat transfer in Microsystems", J. Heat Transf., vol. 129, pp. 101-108, January 2007.

(C) Irakli G. Shekriladze; Licensee Bentham Open.

This is an open access article licensed under the terms of the Creative Commons Attribution Non-Commercial License (http://creativecommons.org/licenses/bync/3.0/), which permits unrestricted, non-commercial use, distribution and reproduction in any medium, provided the work is properly cited. 